\title{
Monitoring cold water injections for reservoir characterization using a permanent fiber optic installation in a geothermal production well in the Southern German Molasse Basin
}

Felix Schölderle ${ }^{1}$, Martin Lipus ${ }^{2}$, Daniela Pfrang ${ }^{1}$, Thomas Reinsch ${ }^{2,4}$, Sven Haberer ${ }^{3}$, Florian Einsiedl ${ }^{1}$ and Kai Zosseder ${ }^{*}$ (D)

*Correspondence:

kai.zosseder@tum.de

${ }^{1}$ Chair of Hydrogeology,

Technical University

of Munich, Arcisstraße 21,

80333 Munich, Germany

Full list of author information

is available at the end of the article

\begin{abstract}
Fiber optic sensing has gained importance for wellbore monitoring and reservoir characterization in geothermal fields as it allows continuous, spatially highly resolved measurements. Distributed acoustic sensing (DAS) and distributed temperature sensing (DTS) technologies, among others, enable monitoring of flow regimes and heat transport inside the wellbore to describe the dynamical behavior of the reservoir. The technically challenging installation of a permanent fiber optic monitoring system in a geothermal production well over the entire wellbore length was conducted for the first time at the geothermal site Schäftlarnstraße in Munich, Germany. One cable with two DAS fibers, two DTS fibers, and one fiber for a downhole fiber optic pressure/temperature gauge were clamped to 3/4-in. sucker rods and installed to $3.7 \mathrm{~km}$ measured depth to collect data from the wellbore after drilling, during testing, and during operations. We present DTS profiles during 3 months of well shut-in and show the results of two cold water injection tests conducted to localize inflow zones in the reservoir and to test the performance of the fiber optic setup. A vertical displacement in temperature peaks of approximately $1.5 \mathrm{~m}$ was observed during the injection tests, presumably resulting from thermal contraction of the sucker rod-cable setup. This was verified by analyzing the strain information from the DAS records over $1 \mathrm{~h}$ of warm-back after cold water injection with the calculated theoretical thermal contraction of DTS of the same period. We further verified the flowmeter measurements with a gradient velocity analysis of DTS profiles during injection. Intake to the major inflow zone was estimated to $93.5 \%$ for the first injection test, respective $94.0 \%$ for the second, intake of flowmeter was calculated to $92.0 \%$ for the same zone. Those values are confirmed by analyzing DTS profiles during the warm-back period after the well was shut.
\end{abstract}

Keywords: Geothermal, Fiber optic monitoring, DTS, DAS, Reservoir characterization, Flow zone, Bavarian Molasse Basin author(s) and the source, provide a link to the Creative Commons licence, and indicate if changes were made. The images or other third party material in this article are included in the article's Creative Commons licence, unless indicated otherwise in a credit line to the material. If material is not included in the article's Creative Commons licence and your intended use is not permitted by statutory regulation or exceeds the permitted use, you will need to obtain permission directly from the copyright holder. To view a copy of this licence, visit http:// creativecommons.org/licenses/by/4.0/. 


\section{Introduction}

The role of renewable energy sources gains importance for climate change mitigation strategies today. About $40 \%$ of Europe's energy demand comes from the heating sector (Kavvadias et al. 2019), for that, regions with high geothermal potential have gained much interest in recent years. To ensure the sustainable use of the geothermal reservoir, a reliable production must be ensured for which well integrity, microseismicity, or thermo-hydraulic interactions inside the reservoir are essential. Understanding subsurface formation conditions is important during drilling, as well as during the production phase, to maintain the system's integrity. Besides that, an accurate reservoir characterization remains one of the most important tasks within a geothermal project to reduce the risk of drilling unsuccessful wells (IGA Services GmbH 2014). Hence, also a reliable regionalizing of determined geophysical properties is essential for further geothermal exploration, defining a productive drilling target, and reducing exploration and drilling risks. In this framework important geophysical properties are, e.g., permeability and porosity of the reservoir matrix and the structure of the reservoir such as fractures. Suitable conditions of these properties create influx zones that feed the geothermal well and make it productive (e.g., DiPippo 2015). To identify and characterize hydraulic active zones, production logging tools (PLTs) are usually run after drilling. Thus, it is possible to identify the location of the flow zones as well as the quantitative contribution of flow from distinctive zones (Grant and Bixley 2011). Most important for flow zone characterization today are spinner flowmeter that measure flow velocities in different depths of a well, from which a flow profile can be calculated. PLTs often also contain temperature tools that can support flowmeter by indicating fluid flow by temperature slope change (Schlumberger 1997). Production logging in open-hole sections and highly deviated wells is difficult to conduct and evaluate (Haoua et al. 2015) and is often not or only incompletely performed due to a high risk of getting stuck. Further characterization and spatial representation of the data can be accomplished by setting the observed hydraulically active zones in the context of lithology, porosity, and fracture analysis. Schlumberger (1997) gives a broad overview of most logging techniques which can be used to interpret feed zones and their application and interpretation. But all of these logs need well intervention and, in the case of high deviations, a rig during measurements to push the tool into the well. During production, such logs are not possible to acquire. Usually, the deepest monitoring system is the pressure gauge installed below the electrical submersible pump (ESP), which is the commonly used in offset wells for this study. Reservoir pressure commonly must be interpolated from ESP measured gauge pressure and estimated reservoir temperature and salinity data (Zarrouk and McLean 2019). Monitoring in the reservoir is not possible for standard well designs.

To combine the concerns of a sustainable and secure reservoir management with the detailed characterization of the reservoir, comprehensive well monitoring is required that can be permanently conducted in a borehole without well intervention, hence the reservoir can be monitored even during operation. Sudden changes in pressure or temperature (e.g., thermal breakthrough) and changes of the chemical composition of the geothermal fluid, e.g., scaling processes (Baticci et al. 2010; Köhl et al. 2020) can reduce or even disrupt successful productivity and affect at least the efficiency of the operation (Zarrouk and McLean 2019). Another important aspect is the observation of dynamic 
processes in flow zones, as characteristics of such zones can irreversibly change after longer production or sudden changes in pressure (Blöcher et al. 2015). Hence, monitoring the reservoir's behavior and the mentioned processes becomes important for plant operators and is also significant for production licenses provided by authorities.

However, implementation of permanent monitoring systems is challenging in production wells with an ESP, as simple wireline constructions do not allow an installation below the pump. Such type of installation must not disturb production, and well intervention must be allowed for ESP changeover without damaging or harming the monitoring system or the well itself. Permanent monitoring can be provided by fiber optic (FO) sensing, which can continuously measure physical parameters with high temporal and spatial in-depth resolution. Additionally, a FO-monitoring system installed inside the borehole to the reservoir offers the possibility of integrating a punctual pressure gauge to measure the reservoir pressure at depth, and allows to avoid rough estimations based on the ESP-gauge pressure. Hence, FO-sensing enables comprehensive short- and longterm monitoring to characterize the reservoir, as well as monitoring of spatial and punctual pressure and temperature changes in the well and reservoir without intervention.

Distributed optical fiber sensors (DOFS) provide near real-time data that capture the dynamics of spatially and temporally varying downhole parameters. In addition to DOFS, fiber optic point sensors can be used to acquire relevant information at the position of the sensor with high accuracy (e.g., Kersey 2000; Qi et al. 2002). Downhole point sensors are typically used to monitor pressure and/or temperature $(P / T)$ at a specified depth in or above the reservoir. Point sensors are often used to acquire high accuracy data at distinct depth in downhole applications. Commonly, combined pressure and temperature sensors are applied (Qi et al. 2002; Kersey 2000). One common type of FOsensors is Fabry-Perot interferometer (FPI) that can be used as a combined pressure and temperature gauge. The sensing principle is based on the reflection of an incident and coherent pulse generated by laser that is reflected at the interface upon entry and exit of a Fabry-Perot cavity. The reflected light interferes and the interference pattern is linearly related to the length of the cavity (Bremer et al. 2010; Qi et al. 2002). If the cavity length changes upon pressure or due to thermal expansion, the interference pattern changes and can be analyzed. Multiplexing, e.g., two cavities in a single fiber, one insulated from ambient pressure and a second subjected to pressure and temperature, allows decoupling both phenomena if properly calibrated. Another sensor type is the fiber Bragg grating (FBG). Liang et al. (2018) give a good description of FBG type sensors-and also combinations of FPI and FBG type sensors exist (Zhou et al. 2012; Bremer et al. 2010). Fiber optic point sensors can be combined with DOFS in a single cable.

For DOFS, distributed temperature sensing (DTS) and distributed acoustic or vibration sensing (DAS) data are acquired in most existing downhole installations. Other applications are static or long-term fiber deformation using distributed strain sensing (DSS) and pressure measurements with distributed pressure sensing (DPS). DSS and DPS will not be discussed in detail here, as only DAS and DTS were realized for this study.

DTS was developed in the 1980s by Dakin et al. (1985), who demonstrated that Raman scattering in an optical fiber can be used for measuring temperatures. Based on either optical time domain reflectometry (Raman-OTDR) or optical frequency domain 
reflectometry (Raman-OFDR), temperature profiles can be acquired with a spatial resolution of about one meter and a temporal resolution of several seconds. For DTS, mostly multi-mode fibers are applied, which usually have a core diameter of $50 \mu \mathrm{m}$ and are suitable for ranges up to $10 \mathrm{~km}$ (e.g., Bense et al. 2008; Smolen and Spek 2003).

Rayleigh and Brillouin scattering have been used to measure the strain changes in an optical fiber, which is the underlying physical principle of DAS systems (Masoudi and Newson 2016). The fibers usually used for DAS are of the single-mode type, which has a smaller diameter of usually $5 \mu \mathrm{m}$ compared to the multi-mode type. It is suitable for longer distances, but more difficult to design and thus more expensive (e.g., Daley et al. 2013; Smolen and Spek 2003).

\section{Application of fiber optic sensing in geothermal wells}

For reservoir monitoring, accurate pressure and temperature measurement at reservoir level is key. FO-sensing is widely used in wells in the oil and gas industry for production surveillance (Buecker and Grosswig 2017), but is still a rare technology for geothermal applications. Thus, FO-systems in geothermal wells are of concern to several scientific studies, but are not yet established as a standard monitoring procedure.

\section{DAS}

Distributed acoustic sensing has been used in downhole applications for structural underground investigations and reservoir monitoring (Barberan et al. 2012; Cox et al. 2012). DAS has also been used to complement and substitute classical geophones in vertical seismic profiling (Daley et al. 2013; Hartog et al. 2014; Madsen et al. 2016; Götz et al. 2018) and has also potential in the field of monitoring production zones (Williams et al. 2015; Naldrett et al. 2018) and flow characteristics (Bukhamsin and Horne 2016). A broader review of DAS applications in wells is given by Lipus et al. (2021).

\section{DTS}

DTS temperature measurements in oil and groundwater wells, production pipelines, and mining areas are well documented in previous studies (Majorowicz and Smith 1999; Kersey 2000; Johnson et al. 2006; Nath et al. 2006; Brown 2009; Inaudi and Glisic 2010; Frings and Walk 2011; Sanders 2011; Ukil et al. 2012; Banks et al. 2014; Lumens 2014; Hartog 2017) as well as the use within the scope of borehole heat exchanger installations for distributed thermal response tests (Fujii et al. 2006, 2009; Acuña et al. 2009; Latal et al. 2011; Hartog 2017; Franco and Conti 2020). Regarding the use of DTS in geothermal wells, laboratory and field tests were carried out in the late 1980s to prove the ability of FO-techniques for temperature and pressure measurements (Angel et al. 1986). After that, DTS has been installed in geothermal wells for various applications, such as for testing DTS systems or assessing lithology in boreholes (Hurtig et al. 1994, 1996; Reinsch and Henninges 2012; Reinsch et al. 2013; Förster et al. 1997; Wisian et al. 1998; Henninges et al. 2005; Freifeld 2008; Siska et al. 2016). Further, a few studies have shown that DTS-measurements in geothermal wells can identify hydraulically active zones and fracture characteristics and measure pressure profiles (Sharma et al. 1990; Sakaguchi and Matsushima 2000; Smithpeter et al. 1999). With the same aims, DTSmeasurements were conducted in combination with cold water injections (Henninges 
et al. 2005; Patterson et al. 2017). The installation of DTS in a geothermal production well was firstly carried out by Smithpeter et al. (1999) using small diameter stainless steel tubing. However, the measurements failed in general due to hydrogen diffusion and a low repeatability. Permanent DTS-measurements are successfully realized by installing the fiber cable behind the borehole casing, but they are then generally limited to the first borehole section (Henninges et al. 2005; Hartog 2017).

For monitoring the wellbore during a longer period of operation, a successful permanent deployment of a DTS system or a general FO-sensing system in a geothermal production well down to the reservoir section would be preferable.

To establish such a continuous measurement of pressure, temperature and acoustic data for monitoring the temperature development in the wellbore and in the hydraulically active zones in the Upper Jurassic reservoir of the Bavarian Molasse Basin in Southern Germany, the present study investigates the set-up of a permanent installation of a fiber optic cable in two wells (producer and injector well) at the geothermal site 'Schäftlarnstraße' in the City of Munich. Apart from the challenge of leading the FO-sensing cable beyond the ESP to the bottom of the deep borehole in order to monitor the entire reservoir section, the production well used was additionally highly deviated. Distributed temperature sensing (DTS) and distributed acoustic sensing (DAS) are successfully implemented along with temperature and pressure data from a fiber optic FPI sensor in the producer well located directly above the reservoir. Two cold water injections were conducted in this study to test the performance of the installed FO equipment and to ascertain inflow zones and compare the results with identified zones from existing flowmeter measurements. Other areas of focus included investigating the warm-back from drilling inside the reservoir to the geothermal gradient during flow-off periods, estimating the reservoir parameters with inverse methods, and testing the ability of the FOsensing setup to detect microseismicity, in case any microseismicity events occur, and to assess well integrity with respect to cementing.

\section{Methods}

We installed fiber optic cables into a geothermal production and injection well and used DTS data measured after drilling and during shut-in after cold water injection to observe the temperature distribution within the production well. To test the overall performance of the FO-installation and characterize the flow zones in the reservoir, we analyzed DTS and DAS data during two injection tests that were performed in early 2020. We further estimated an inflow profile by analyzing flowmeter data from July 2019 together with FO-DTS data from injection tests. We used temporally integrated DAS strain rate data to detect whether and how the FO-system is subject to thermal contraction/expansion.

\section{Description of the study site conditions and wells}

Since about two decades, the Upper Jurassic carbonates of the Bavarian Molasse Basin in Southern Germany are the target for geothermal exploration as they provide favorable geological conditions for hydro-geothermal projects (Steiner et al. 2014). The sedimentary layers of the aquifer partly show very good hydraulic properties, providing hot water with temperatures up to $>160{ }^{\circ} \mathrm{C}$ (Weber et al. 2019). Accordingly, many geothermal projects were realized in recent years, most of them in the Munich metropolitan region, 
which together deliver a thermal output of $322 \mathrm{MW}$ and an electrical power of $35 \mathrm{MW}-$ as of 2020 (Flechtner et al. 2020). Further geothermal projects are planned in the greater Munich area to reach the vision of the City of Munich having a $\mathrm{CO}_{2}$ emission-free district heating network by 2040 (Kenkmann et al. 2017).

The Bavarian Molasse Basin is an alpine foreland basin extending from the northern alpine rim northward to the Swabian and Franconian Alb where it emerges (Meyer and Schmidt-Kaler 1990). In the Upper Jurassic, carbonates were deposited on a carbonate platform in the Tethys Sea. Today, sequences of limestone, marl and dolostone form two different facies types, a massive reef facies with a high rock matrix porosity and a bedded facies that is composed by lower matrix porosity (Meyer and Schmidt-Kaler 1990). As a potential aquifer, dolomitized massive facies is a preferable geothermal exploration target in the Molasse Basin (Böhm et al. 2013) and can be explored in the middle layers of the Upper Jurassic (referred to as Malm Delta and Epsilon), as well as in the uppermost layers (referred to as Malm Zeta 1-6). Malm Zeta is overlaid by carbonates of the Purbeck facies that formed due to evaporation as the shelf sea dried out at the end of late Jurassic (Meyer and Schmidt-Kaler 1990; Mraz 2018) and can also bear a potential hydrothermal reservoir (Böhm et al. 2013).

Multiple studies of the reservoir, comprising hydrochemistry analyses, overpressure conditions, and hydraulic and geophysical characterizations, pointed out that the Malm geothermal reservoir shows partly strong heterogeneous conditions in terms of changing porosity, permeability, and variable flow zones from matrix-dominated flow to prevalent fracture and karstic flow (Birner et al. 2013; Drews et al. 2018; Bohnsack et al. 2020; Heine et al. 2021; Konrad et al. 2019, 2021). Moreover, analyses of the geothermal wells in the Malm have shown that karstification and a reasonable matrix permeability, existing preferentially in the reef facies, are key factors for productivity. Faults and/or associated fracture zones seem to play a subordinate role for well productivity in the greater Munich area, but may play a dominant role in the southern part of the Molasse Basin (Wolfgramm et al. 2009; Böhm et al. 2013, Konrad et al. 2021). Hence, the identification and monitoring of flow zones and their contribution to the productivity in a geothermal well is an important factor to further characterize the reservoir and improve targeting and reservoir engineering in the Malm reservoir.

The geothermal site Schäftlarnstraße in downtown Munich, Germany, located in the middle of the Bavarian Molasse Basin, consists of six wells (three producers and three injectors) and explores the carbonates of the Upper Jurassic Malm reservoir described above as well as the overlying Purbeck formation. Malm Zeta reservoir is in a depth of 2250 to $2550 \mathrm{~m}$ depth below surface and the expected production temperature is about $100{ }^{\circ} \mathrm{C}$. To improve the exploitation of the reservoir and keep distance between production and injection, all wells in this project are deviated. Two of six wells at the site were used for the installation of fiber optic monitoring systems. In well 1 (production well) cables were installed from top to the end of the reservoir section inside the wellbore and in well 2 (injection well) in the top section behind the 20-in. casing. Well 1 is completed with a 20 -in. anchor casing, a 13 3/8-in. casing, a 9 5/8-in. liner and a perforated 7 -in. production liner. Kick-off points of the deviated well are at $250 \mathrm{~m} \mathrm{MD}$ ( $4^{\circ}$ inclina-

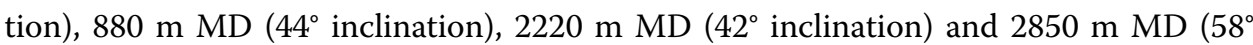


inclination). The total measured depth of the well is $3741 \mathrm{~m}$, which corresponds to a true vertical depth (TVD) of $2947 \mathrm{~m}$.

Well 2 has a depth of $4443 \mathrm{~m} \mathrm{MD} \mathrm{(2722.8} \mathrm{m} \mathrm{TVD)} \mathrm{and} \mathrm{is} \mathrm{completed} \mathrm{with} \mathrm{a} \mathrm{20-in.}$ anchor casing, a 13 3/8-in. casing and a $95 / 8$-in. liner. The reservoir section that was drilled with an 8.5-in. bit is a completed open-hole. An overview of the completion of both wells including kick-off points is given in Additional file 1: Appendix S1.

Table 1 shows the well history for the relevant sections where the FO-system was installed in both wells. After completion, several logging runs were conducted in the reservoir section of well 1, including Resistivity Micro Image Log, Caliper, Gamma Ray, Sonic Log and Nuclear Magnetic Resonance (NMR) (only in the upper $100 \mathrm{~m}$ of the reservoir). Hydraulic testing with airlift started shortly afterwards. Thereafter, a production logging flowmeter temperature run was performed. The well was shut and a wireline temperature $\log$ run was performed after 3.5 months. This temperature log reaches only to $2819 \mathrm{~m}$, as the tool could not pass the 7-in. liner hanger.

\section{Implementation of the fiber optic monitoring system}

The completion of the production well and the relevant well section of the injection well with fiber optic cables are shown in Fig. 1.

Due to the high deviation, reaching total depth (TD) with the FO-installation was challenging. To minimize the risk and successfully land the cable, a perforated liner was installed in the reservoir section of well 1 , unlike the open-hole completions done in most of the other five wells at the site. In advance of the installation, a conventional wireline temperature log was performed for comparison. At this time, a temporarily 13 3/8in. 'tieback' liner was inside the first section of the well, which was pulled just before installing the FO downhole cable. After successful FO-installation to TD in well 1, the drilling rig was skidded to well 2. After drilling the first section, a second fiber optic cable was permanently installed behind the casing and cemented in place in well 2 (see blue 'Flatpack' line in Fig. 1).

To achieve the objectives mentioned above, the installation in the second well was used to investigate the temperature distribution and evolution while cementing and the warm-back of the borehole to the geothermal gradient until the start of injection. Also the temperature distribution while injecting, as well as acoustic measurements to monitor potential microseismicity were investigated. The analysis of these measurements in

Table 1 Excerpt of the well history of well 1 and well 2

\begin{tabular}{llll}
\hline Well 1 (producer) & Well 2 (injector) & \\
\hline $\begin{array}{l}\text { Completion of drilling open } \\
\text { hole }\end{array}$ & 4 June 2019 & $\begin{array}{l}\text { Completion of drilling first } \\
\text { section }\end{array}$ & 24 November 2019 \\
Logging in reservoir section & 15 to 21 June 2019 & $\begin{array}{l}\text { Construction of FO cable } \\
\text { June and July 2019 }\end{array}$ & 28 to 29 November 2019 \\
Hydraulic testing & 10 July 2019 & & 30 November 2019 \\
Flowmeter logging & 23 October 2019 & \\
Wireline temperature log & 24 to 31 October 2019 & \\
Installation of FO cable & 23 January 2020 & \\
Cold water injection test 1 & 22 February 2020 & \\
Cold water injection test 2 & &
\end{tabular}




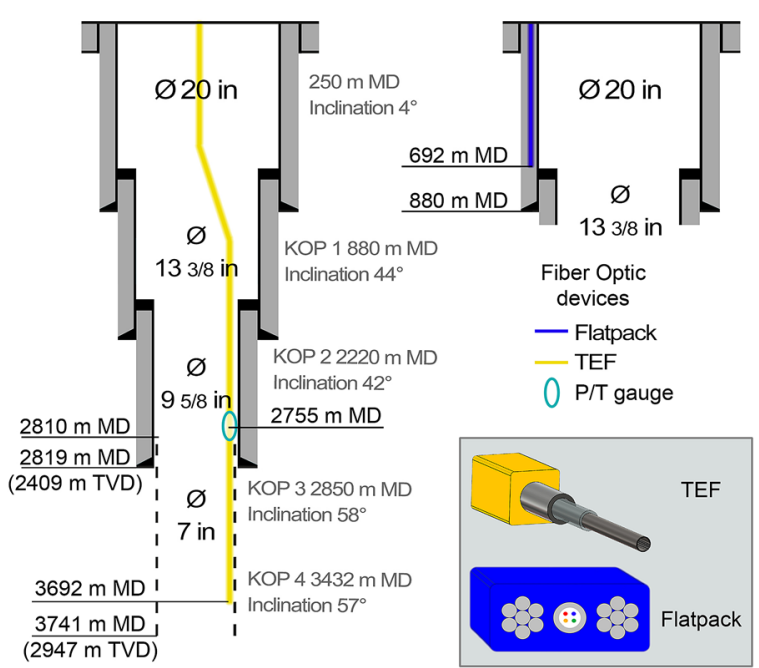

Fig. 1 Completion of production well 1 (left) and injection well 2 (right) with equipped fiber optic cables in Munich with relevant depths and kick-off points (KOP). Blue: with bumper wires equipped flatpack cemented (gray) behind the casing in injector well. Yellow: tubular encased fiber (TEF) installed along sucker rods to TD in producer well. Turquoise: fiber optic P/T gauge. Sketches of TEF and Flatpack are shown in gray box

well 2 are not part of this study, as it focuses on the overall performance of the FO-system and reservoir characterization, respectively, the detection of the flow zones. Hence the measurements presented and discussed in this study were carried out in producer well 1. Nevertheless, construction of the cemented FO-cable is described, as the fibers of both wells producer and injector, form one monitoring system at the site.

\section{Downhole cable}

An installation in a geothermal well to total depth poses specific challenges to the FOcable, as it is exposed to harsh conditions like chemical and physical stress from the high pressure and high-temperature thermal water (e.g., Smithpeter et al. 1999). To withstand these conditions, the single-mode and multi-mode fibers were specially designed for applications in oil and gas fields, providing high resistance to the harsh environment in boreholes and ensure long-term reliability, e.g., resistance to hydrogen darkening (Smithpeter et al. 1999). The fibers are protected by a 1/4-in. stainless steel tube. This tubing encased fiber (TEF, see sketch in gray box in Fig. 1) in producer well 1 is encapsulated with $11 \times 11 \mathrm{~mm}$ polypropylene for ease of installation and additional protection. The TEF was designed for a maximum temperature of $150{ }^{\circ} \mathrm{C}$ and pressures up to $20 \mathrm{kpsi}(1375 \mathrm{bar})$ as per the expected well and reservoir conditions. It contains two double-ended multi-mode fibers for DTS, two single-mode fibers for DAS (one of those as backup) and one single-mode fiber for the fiber optic $P / T$ gauge located right at the top of the reservoir (2755 m MD, see Fig. 1). For the FO-installation outside the casing in the injector well, additional cable protection was chosen to withstand the high potential drag torque forces of the 20-in. casing during installation. This was achieved by packaging the 0.25 -in. TEF with two protective 0.375 -in. bumper wire in a so-called 'flatpack' (see sketch in gray box in Fig. 1). The TEF in the flatpack contains two singlemode fibers for DAS and two multi-mode fibers for DTS. To allow a double-ended fiber 
configuration, the fibers are bent $180^{\circ}$ at a low profile. This 'mini-bend' at the bottom end of the cable enables measuring in both wells in one daisy chain system (e.g., Götz et al. 2018).

Since the fibers are subjected to less physical and chemical stress once they are routed out of the borehole, the downhole cables are connected to a simpler surface cable at the wellheads of wells 1 and 2 .

\section{Installation behind the casing of the injector well}

Special clamps were used to provide mechanical protection at each connection of the casing. Also special non-rotating centralizers were used to prevent damaging the TEF during installation. During installation, cable integrity was monitored with continuous OTDR measurements. After run in hole, the casing was cemented in, with this cementing process being recorded using both DAS and DTS. The downhole TEF is connected to the surface cable using a vent-box, which protects the fiber splices is mounted to the wall of the borehole cellar.

\section{Installation inside producer well}

The installation of the TEF to total depth of the producer well was planned in close cooperation with the geothermal operator. The major challenge was to design a monitoring system that would cover the entire length of the borehole, including the reservoir section, without interfering with well production and with proper routing below the ESP as well as beyond the liner hangers of each casing section. During the planning phase, the additional pressure loss due to friction of the FO-construction and narrowing of the effective flow area inside the borehole was estimated at worst case 3.5 bar. For a reservoir pressure of around 215 bar, as measured by pressure logs and confirmed by the FO-P/T gauge (see Ch. 2.3), this results to around $1.5 \%$ additional loss. The main components of the FO-construction are shown in Fig. 2.

To ensure the TEF reaches TD in a nearly straight line as well as for mechanical protection, while minimizing flow restrictions, the TEF was mounted to sucker rods [see (c) in Fig. 2].For the first phase, these sucker rods were suspended from the tubing hanger via a crossover [see (a) in Fig. 2]. For the ESP-installation, the top sucker rods will be pulled and removed, with the remaining sucker rods then being connected to below the ESP and production tubing, ideally without breaking the TEF.

The 3/4-in. sucker rods are each 30 foot in length with four pre-installed nylon-centralizers to guide the TEF along the rods. To ensure controlled routing of the TEF from the cable drum to the rig floor, it was run over a sheave held by a crane, while the sucker rods were installed using the rigs top-drive and were torqued together via couplings to install the FO-cable from bottom to top. At every sucker rod connection, the TEF was fixated with special clamps [see (a) and (c) in Fig. 2] and with heat-resistant plastic strips, leaving a bit of excess length to the cable to allow for thermal expansion of the sucker rods. Therefore, sucker rod length and cable length differ, requiring careful localization of the measurements. At the downhole end of the sucker rods, a carrier [length $1.42 \mathrm{~m}$, diameter $0.15 \mathrm{~m}$, see (d) in Fig. 2] protects the termination of the DAS fibers as well as the pre-installed mini-bend for looping the multi-mode fibers. The centralizer at the carrier allowed a successful run-in-hole across all liner hangers. To install the $P / T$ 

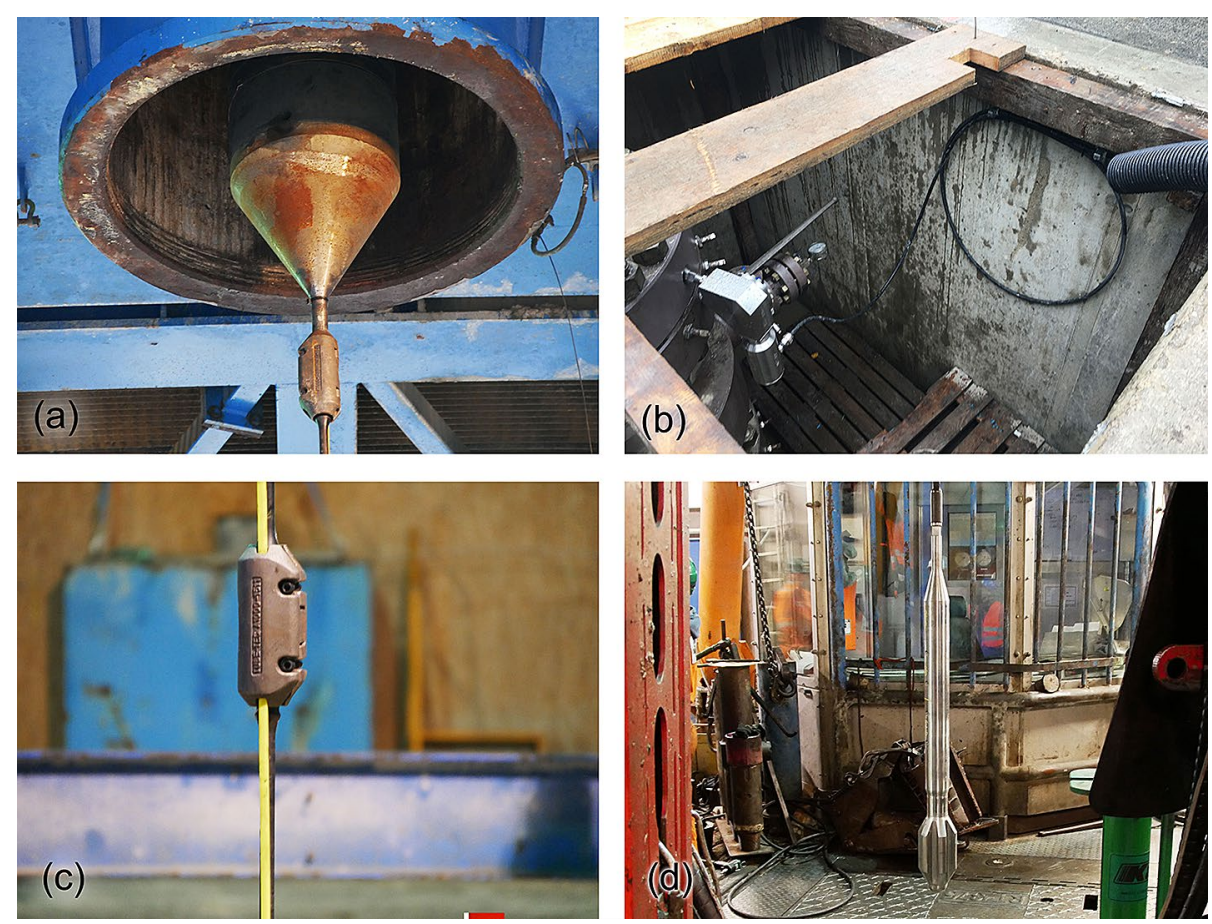

Fig. 2 Installation of the FO-cable in the producer well. a 3/4-in. to 13 3/8-in. crossover. b Wellhead outlet. $\mathbf{c}$ TEF mounted on sucker rods with clamps. $\mathbf{d}$ Carrier at termination with centralizer

gauge at the desired depth directly above the reservoir, the sucker rod installation was interrupted, the TEF was cut, and the fibers were spliced to the gauge. The sensitive fiber splices were protected in a specially designed splice-carrier. The gauge and the splicecarrier were inserted in a 1.59 -m-long carrier that was torqued to the sucker rods. At the top of the sucker rod string, the crossover [see (a) in Fig. 2] was suspended from the tubing hanger. The TEF was guided on the outside of the tubing and passed through the hanger. There it was bent $90^{\circ}$ in a controlled manner so that it could exit horizontally from the wellhead collar through the specially designed fiber optic wellhead outlet [FOWHO, see (b) in Fig. 2]. The FO-WHO is installed on the side of the wellhead and allows the downhole fibers in the stiff TEF to be connected to the more flexible surface fiber cable via a pressure barrier. To ensure that the TEF was not damaged during run-in hole, the fibers were continuously monitored via OTDR and a 'fiber optic rotary joint' (FORJ), a connection that allows free rotation along the cable axis.

Additional direct OTDR and DTS measurements were performed at regular intervals to check the fibers' integrity, as the FORJ added noise. This surveillance detected a deteriorating splice at the $P / T$ gauge, thus the string was pulled and the splice redone.

The installation was successfully completed in November 2019 and a first DTS profile fits to the wireline temperature log recorded 1 week before (see light gray curve in comparison to red curve in Fig. 3 in Ch. 2.3).

\section{Performance of the FO-system and calibration}

Repeated OTDR measurements were conducted whenever necessary to check the integrity of the fiber optic system, e.g., after completion of the installation, after repair works, 


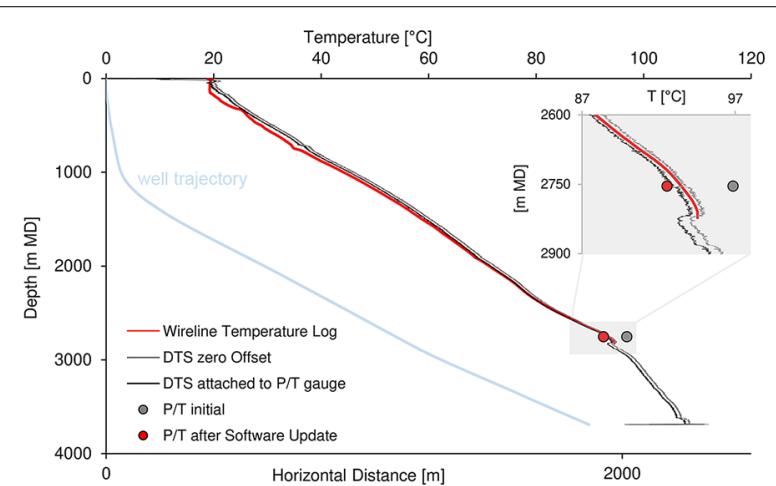

Fig. 3 Calibrated and non-calibrated DTS profiles of the Schäftlarnstraße site in comparison to P/T gauge data before and after software update

or prior to specific tests at the site. The OTDR tests showed a uniform loss of the optical power level between the splices and fiber connectors along the fiber, indicating good backscattering behavior of the cable. The splice at the $P / T$ gauge and the splices at the wellhead produce about $0.8 \mathrm{~dB}$ loss. A higher loss can be observed at the mini-bend in the injector well, which is about $1.3 \mathrm{~dB}$. This mini-bend had to be installed on site in comparison to the mini-bend of the TEF in producer well 1 that was pre-installed in the workshop under controlled conditions. Overall, the loss along the multi-mode fibers inside the producer well is about $0.7 \mathrm{~dB} / \mathrm{km}$, in the injector well higher with $1.18 \mathrm{~dB} /$ $\mathrm{km}$ (due to the higher loss at the mini-bend). Along the single-mode fiber, the loss is approximately $0.75 \mathrm{~dB} / \mathrm{km}$. Exemplary OTDR measurements of the multi-mode (DTS) fibers in the producer well and of the daisy-chained single-mode (DAS) fibers ending at total depth of the producer well are attached in Additional file 2. The OTDR measurements show that the fiber optic system allows precise DTS and DAS measurements in the deviated production well.

\section{Resolution of FO-measurements}

A DTS interrogator, a $P / T$ interrogator, and a DAS interrogator are installed as measurement devices at the study site. The performance of DTS depends on the temperature resolution and the spatial resolution. The laser pulse width specifies the minimum sampling interval, defined as the length increment, for which traces can be recorded. Spatial resolution, on the other hand, is the integrated distance a system needs to fully represent a temperature change (e.g., Smolen and Spek 2003). The DTS interrogator at the study site is an AP Sensing Linear Pro Series N4386B unit with a maximum measuring range of $12 \mathrm{~km}$. The unit works on Raman-OTDR backscattering. With the given configuration (double-ended fiber and measuring range of about $8 \mathrm{~km}$ ), the interrogator allows a spatial sampling of $0.25 \mathrm{~m}$ at a spatial resolution of $1 \mathrm{~m}$. The temperature resolution is mainly dependent on the acquisition time and increases with longer measurement times (e.g., Smolen and Spek 2003). In our case, DTS traces are acquired every $10 \mathrm{~min}$. At this temporal resolution and spatial resolution of $1 \mathrm{~m}$ the dispersion of DTS values in field shows to be $\pm 0.6 \mathrm{~K}$. After averaging the data over time intervals of $6 \mathrm{~h}$ the temperature resolution is about $0.13 \mathrm{~K}$. This is roughly on the same order of magnitude as other reported DTS installations in geothermal wells, e.g., Henninges et al. 
(2005) gave a resolution of $0.06 \mathrm{~K}$ for their DTS installation in the Groß Schönebeck borehole (where temperature data were averaged over time intervals of $2 \mathrm{~h}$ ). The $P / T$ interrogator installed at the study site is a SureView PT Gen3 unit. $P / T$ data are acquired every second and averaged over $10 \mathrm{~s}$. Resolution of the data in field shows to be $0.06 \mathrm{~K}$, respectively, 0.8 bar. The absolute accuracy of the $P / T$ gauge as specified by the manufacturer is $\pm 5 \mathrm{psi}$ ( $\sim 0.34$ bar). The DAS interrogator was a Silixa iDAS device that uses Rayleigh backscattered photons (phase-OTDR) by measuring the phase difference changes between the beginning and end of any section of the optical fiber (e.g., Masoudi et al. 2013). Key parameters to the performance of DAS are sampling frequency, gauge length, and spatial sampling, which were $1000 \mathrm{~Hz}, 10 \mathrm{~m}$, and $1 \mathrm{~m}$, respectively.

\section{Depth allocation}

For fiber optic distributed sensing, each measurement trace needs to be located at depth (Smolen and Spek 2003). The recorded DAS and DTS traces begin at the respective interrogator. As there are several meters of surface cable between the interrogator and the wellhead (146 m to production well, $143 \mathrm{~m}$ to injector well), the exact position of the well inlet on a FO-measurement must be determined. For DTS, a cooling spray was used to mark specific points on the measurements, located at short known distances from the wellhead outlet. For the injector well, the temperature marker was set $6 \mathrm{~m}$ before the inlet to the cementation at the bottom of the drilling cellar, $2.5 \mathrm{~m}$ below ground level. For the producer well, the temperature marker was $1.5 \mathrm{~m}$ before the wellhead outlet, which is $0.5 \mathrm{~m}$ below ground level. The end of the DTS traces is located at total well depth, which is known from drilling tally. For well 1 , this is the length of the installed sucker rod construction, which is $3690.2 \mathrm{~m}$. For well 2, the end of the traces is given as the length of the casing along which the flatpack was installed, which is $692.0 \mathrm{~m}$. The recorded DTS traces are separated into surface and downhole section and further processed. Depth locations were set by linear interpolation between the wellhead and the bottom of the installation. For DAS, an acoustic knocking noise ('tap test') on the FOWHO was recorded to exactly determine the surface depth reference (e.g., Götz et al. 2018). At a gauge length of $10 \mathrm{~m}$ with a spatial sampling of $1 \mathrm{~m}$, the acoustic signal related to the tabs is spread out over several meters, which leads to a smearing over a few meters at the wellhead, resulting in an error of approximately $\pm 2 \mathrm{~m}$.

\section{Temperature calibration}

At the beginning of the project, it was planned to use the $P / T$ gauge as a temperature calibration point for the DTS in the downhole section. However, first gauge measurements showed temperature values exceeding those of DTS by almost $4 \mathrm{~K}$ (see the deviation of the red circle and gray circle in Fig. 3). Figure 3 shows the first DTS profiles compared to the incomplete wireline temperature log (the logging tool could not pass the 7 -in. liner hanger, see Ch. 2.1) and the $P / T$ gauge temperature data.

As DTS profiles showed good agreement with the conventional wireline temperature $\log$ run 1 week prior to the completion FO-installation (see Table 1), it was considered that the measurement of the gauge was inaccurate and there might be a problem with the gauge's hardware or software or the $P / T$ interrogator. In early 2020 the manufacturer of the gauge delivered a software update which improved the $P / T$ data by $-4.3 \mathrm{~K}$ and 
+0.73 bar. After this, the DTS was calibrated to the gauge data at the respective depth (see dark gray curve in Fig. 3). With that, DTS data on top of the reservoir showed to be $0.7^{\circ} \mathrm{C}$ lower than the wireline temperature log. The software update of the gauge shifted the temperature values to better agreement with DTS and the independent wireline log. By aligning the wireline temperature log with repeated DTS measurements, the previous readings of the $P / T$ gauge could be verified and corrected.

\section{Flowmeter logging}

We used flowmeter analysis for hydraulic active zone characterization and compared the results with DTS and DAS data of the FO-monitoring system. Raw flowmeter data (uncalibrated) were available from a full-bore flowmeter run on 11 July 2019, with three calibration runs of each of the first and last $60 \mathrm{~m}$ of the reservoir section, one flowmeter log over the entire section, and corresponding temperature runs. Injection rate during the flowmeter run was $50 \mathrm{l} / \mathrm{s}$.

Usually flowmeter logs are run when a stable injection rate and pressure is reached, but this can sometimes not be achieved due to operational constraints. The recording of spinner responses at different logging speeds (at least three) enables to calibrate the spinner and to allow quantitative interpretation (Schlumberger 1997). As the injected fluid enters karstified, porous and/or fractured zones, the impeller motion of the flowmeter can point to inflows and outflows at the respective depth of the tool. For this study, flow zone interpretation was done following the basic workflow of the commonly used petrophysical software environment KAPPA Emeraude (v5.20.03), which is based on interpretation techniques as described, e.g., in Schlumberger (1997). As common, only the smoother upwards run was used for interpretation. First the spinner was calibrated in a zone with constant cable speeds and spinner velocities, resulting in a spinner threshold of $\pm 0.818 \mathrm{~m} / \mathrm{min}$. Based on this calibration and by considering the exact borehole diameter from the caliper curve, the revolutions per second (RPS) measured by the impeller were translated into continuous rate calculation profile as a function of depth. From this injection profile, schematic inflow zones were inferred considering geological background knowledge from geophysical loggings, as a sonic interpretation using the petrophysical software package Interactive Petrophysics (4.5.5). Since no other porosity tool, e.g., density, neutron, was performed over the entire borehole section, the sonic log was used to calculate the matrix porosity of the formation. The resulting matrix porosity was cross-checked against available laboratory porosity measurements of 19 sidewall core samples from this borehole using Wyllie's equation (Wyllie et al. 1956) with matrix interval times of $47.6 \mu \mathrm{s} / \mathrm{ft}$ for limestone and $43.5 \mu \mathrm{s} / \mathrm{ft}$ for dolomite (Cannon 2015). In addition, the flowmeter temperature log was considered, since inflows are reflected in a slope change on the temperature profile (e.g., Grant and Bixley 2011; Zarrouk and McLean 2019).

\section{Cold water injection tests}

After more than 6 months of shut-in (after flowmeter run, see Table 1), fresh water was injected freefalling into the well to artificially disturb the temperature equilibrium of the well. The focus was to verify flowmeter data with a high temperature 
gradient and to record the warm-back profile with DTS, as well as listening to the acoustic response with DAS. The initial water level was about $170 \mathrm{~m}$ on 23 January 12:00.

The first hydraulic test took place on 23 January at $14: 22$. Altogether $1350 \mathrm{~m}^{3}$ of about $10{ }^{\circ} \mathrm{C}$ fresh water were injected into the borehole, without rising the water level to the borehole collar, using two standard hoses connected to the mains water supply. The injection duration was $24 \mathrm{~h}$ and the pumped volume was monitored every $2 \mathrm{~h}$. The mean injection rate was about $16 \mathrm{l} / \mathrm{s}$. Due to memory and connection problems, DAS data could only be collected at the beginning, but not for the entire duration of the test. To obtain a complete data set for both DAS and DTS, a second injection test was performed on 22 February from 00:56 to 23 February 01:00. The test setup was the same as in January, except for a higher flow rate of about $23 \mathrm{l} / \mathrm{s}$ compared to the first injection test. Pumped volume was monitored every hour to assure a constant flow rate. In total, $1995 \mathrm{~m}^{3}$ fresh water were injected without rising the water level to the borehole collar throughout the entire test. In the following, the two injection tests are named Inj1, which is the first test carried out in January, and Inj2, which represents the second test in February.

Gauge data and flow rates are depicted in Fig. 4 for the two injection tests, including a shut-in time of $41 \mathrm{~h}$. Initial pressure at the gauge was $215.3 \mathrm{bar}$. The recorded temperature data clearly reflect a rapid cooling of the fluid inside the borehole from surface to top reservoir immediately after start of cold water injection. After $2 \mathrm{~h}$ of injecting, the water was cooled down by $35 \mathrm{~K}$ and $45 \mathrm{~K}$ for Inj1 and Inj2, respectively. The temperature decline during the second test was faster, indicating a faster cooling, probably due to the higher injection rate during Inj2. After $6 \mathrm{~h}$, the temperature curves of Inj1 and Inj2 remain almost constant. As the well was shut, the water temperature quickly increased at the $P / T$ gauge and began to equilibrate back to formation temperature. At this time, the well was cooled at reservoir level during Inj1 by $65.5 \mathrm{~K}$ and during Inj2 by $69.5 \mathrm{~K}$. As there were only 29 days between the shut-in of

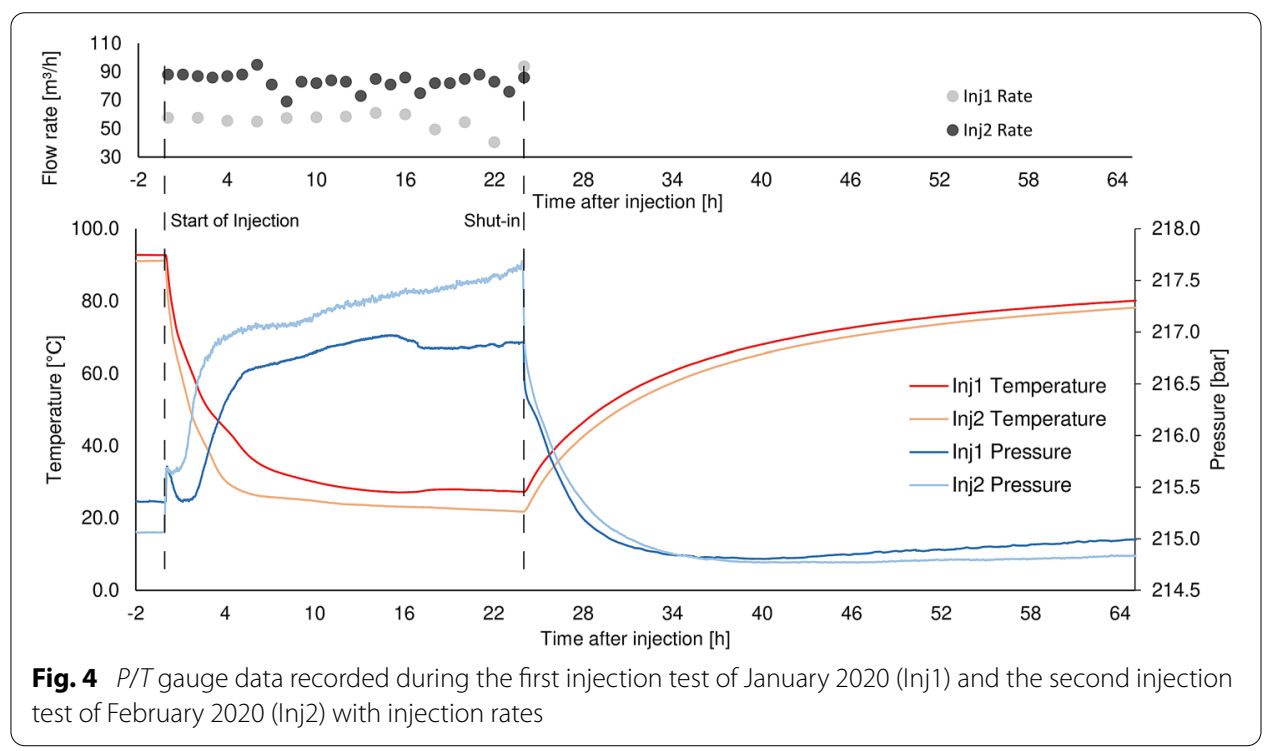


Inj1 and the start of Inj2, the well temperature was not in equilibrium with the undisturbed formation temperature. Therefore, the initial temperature of Inj2 was $1.5 \mathrm{~K}$ lower compared to the initial temperature measured before Inj1.

\section{Thermal dynamics of the FO-construction}

To test if the sucker rod/FO-cable construction has been subject to thermal contraction (due to cold water injection) and thermal expansion (heating after shut-in), we calculated a theoretical thermal strain from DTS and compared this with DAS measured and temporally integrated strain rate along the fiber. The theoretical contraction/expansion, respective strain $\varepsilon_{\mathrm{DTS}}(\mu \varepsilon)$ to which the downhole FO-construction is exposed due to the cooling or heating can be calculated with Eq. 1 by multiplying the temperature deviation of two DTS profiles $\Delta T_{\text {DTS }}(\mathrm{K})$ with a thermal expansion coefficient $\alpha_{\mathrm{th}}\left(\mu \frac{\varepsilon}{\mathrm{K}}\right)$ of the relevant material according to, e.g., James et al. (2001):

$\varepsilon_{\mathrm{DTS}}=\alpha_{\mathrm{th}} * \Delta T_{\mathrm{DTS}}$.

The downhole construction consists of sucker rods, TEF, centralizers and clamps. To simplify the calculations, we neglected the thermal-mechanical properties of centralizers and clamps and assumed the sucker rod and steel of the cable to be the main construction part. A thermal expansion coefficient $\alpha_{t h}$ of $13 \mu \varepsilon / \mathrm{K}$ was applied for the sucker rod 4332 SRX nickel-chrome-moly steel (Cverna 2002). The resulting strain profile shows the theoretical expansion of the sucker rod due to heating. Negative strain can be translated as contraction, positive strain as expansion.

To check if this expansion is actually experienced by the fiber or if the fiber remains in place and thermal stresses build-up, the DAS strain rate data were integrated over the same time period to a cumulative strain $\varepsilon_{\text {DAS }}$. DAS, as used in our application, analyses the phase of elastically backscattered photons by measuring the phase difference between the beginning and end of any section of the optical fiber. External forces (e.g., strain) that perturb this section result in phase difference changes (Masoudi et al. 2013). Raw measured strain rate can be converted to a DAS strain $\varepsilon_{\text {DAS }}$ at a distinct location by integrating in time. This integration entails the risk of systematic error due to a drift of the acquisition unit. Lipus et al. (2021) referred to this and relativized the risk of such error as they saw no strain accumulation to the very end of the installation where no thermal contraction is expected.

\section{Temperature interpretation and warm-back analysis}

When cold water is injected, the temperature equilibrium of a well gets disturbed. The cooling process in the reservoir section differs according to the characteristics of the wellbore environment. Low permeability zones are getting cooled by the conduction of heat from the fluid to the formation, while high-permeability zones are cooled due to the heat advection current of the fluid that flows into these zones. Major temperature responses can be seen in such zones (e.g., Sakaguchi and Matsushima 2000; Henninges et al. 2005; Hole 2008; Patterson et al. 2017).

To localize hydraulically active zones with the FO-system, we analyzed the cooling within the reservoir during the injection period and analyzed the propagation of the cold front of the injected freshwater. As we follow the cold water down the borehole, we 


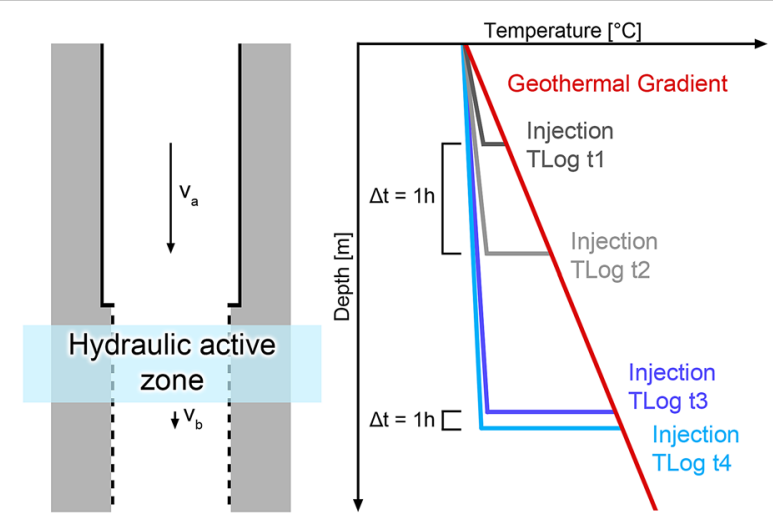

Fig. 5 Schematic DTS velocity track analysis during injection of cold water. Dark gray and light gray lines are DTS temperature logs (TLog) at different times $\mathrm{t} 1$ and $\mathrm{t} 2$ and show the downhole propagation of injected cold water in the cased section of a well. Dark blue and light blue lines are DTS profiles at later times t3 and t4 below a feed zone. $v_{a}$ and $v_{b}$ are the velocities above and below the hydraulic active zone

expect a moving cold front along the borehole axis. Figure 5 shows a scheme of the performed DTS velocity track analysis with the gray and blue lines representing DTS profiles at different times after the start of cold water injection above a hydraulically active zone (gray lines) and below the zone (blue lines).

From the distance covered by the injection front, a velocity ( $v_{a}$ and $v_{b}$ in Fig. 5) can be estimated. At zones with high permeability (hydraulically active zones), the vertical moving thermal front should change in terms of velocity and a slowdown should be noticeable (Ali et al. 2013). In Fig. 5, this is reflected by the fact that the velocity below the hydraulic active zone $v_{b}$ is lower than the velocity above in the cased section $v_{a}$. We applied this graphical analysis to both injection tests Inj1 and Inj2. For verification, the flow velocities inside the well were also estimated from the injection rates and the area inside the borehole. For simplifications, the flow area was assumed as a concentric circular ring. With hydraulic diameter $d_{h}=d_{C, i}-d_{\mathrm{FO}}$ and assuming uniform turbulent pipe flow, the mean flow velocity for such is given by Eq. 2 (e.g., Bohl and Elmendorf 2005):

$$
v_{i}=\frac{Q * 4}{\left(d_{C, i}^{2}-d_{\mathrm{FO}}^{2}\right) * \pi},
$$

where $v\left(\frac{\mathrm{m}}{\mathrm{h}}\right)$ is the velocity, the index $i$ is the respective borehole section, $Q\left(\frac{\mathrm{m}^{3}}{\mathrm{~h}}\right)$ is the flow rate, $d_{C}(\mathrm{~m})$ is the inner diameter of the casing, and $d_{\mathrm{FO}}(\mathrm{m})$ is the diameter of the installed FO-construction. The cross-section of the sucker rod/TEF was simplified as a circle with a diameter of $0.03 \mathrm{~m}$ (0.43-in. TEF mounted to the 3/4-in. sucker rod).

To qualitatively characterize the located hydraulic active zone, we calculated the ratio $I(\%)$ of velocities above $v_{a}\left(\frac{\mathrm{m}}{\mathrm{h}}\right)$ and below $v_{b}\left(\frac{\mathrm{m}}{\mathrm{h}}\right)$ the zone that were estimated from the DTS velocity track analysis (see Fig. 5) and derived from velocity calculations (see Eq. 2) according to Eq. 3:

$$
I=\left(v_{a}-v_{b}\right) / v_{a} .
$$

In analogy to the flowmeter analysis, the total volume injected into the formation was estimated from the flow rate and calculated ratio $I$. 
To analyze the dynamics of the reservoir in a time-resolved manner, in particularly located hydraulic active zones, we observed the warm-back of the water column to the initial formation temperature after well shut-in. This was essential to provide information about the temperature distribution inside the well that is dependent on time, the rock's thermal properties and its hydraulic properties.

\section{Results}

The downhole FO-monitoring system was successfully installed in the highly deviated well without damaging the fibers or the wellbore. Continuous monitoring started 11 days afterwards (see Table 1). With exception of 1-month downtime in March 2020 during the rig-down of the drilling rig, $P / T$ gauge data and DTS data were recorded from November 2019 until August 2020. DAS was only recorded during the injection measurement campaign, as well as other testing works on the site. For Inj1, the DAS dataset is incomplete, and only covers the beginning of the test. For Inj2, a complete DAS dataset is available.

The results presented here are structured in flowmeter interpretation for a comparison with the DTS/DAS dataset, DTS-measurements as the well was shut, outcomes of the cold water injection tests and verification of the hypothesis of the dynamical behavior of the FO-structure to thermal stress.

\section{Flow zone detection by flowmeter logging}

Flowmeter measurements were conducted to identify hydraulically active zones in the reservoir section, and they were used to match the DTS/DAS measurements to the results. Figure 6 shows the raw flowmeter data (logging speed, rotation of spinner and corresponding temperature log, all from July 2019), the resulting injection rate profile (light blue), and the interpreted injection zones (purple zones).

The interpreted main injection zone (1 in Fig. 6) is located in the stratigraphic formation Purbeck in the uppermost of the reservoir section. This karst-dominated zone has a length of $15 \mathrm{~m}$ MD (see green box inside Fig. 6). Here, the flowmeter measurements detected that about $92 \%$ of the injected water flowed into the formation. Although the flowmeter temperature curve shows a rapid increase below $2900 \mathrm{~m}$, the rotation of spinner curve does not highlight an additional injection zone, as the spinner response was quite low $(<1 \%$ inflow). This behavior might be related to a slight change in logging speed. Only about $8 \%$ inflow could be assigned to regions in deeper reservoir sections. One can be located at the transition of Malm Zeta 3 to Zeta 2 (zone 2 in Fig. 6) and another one from 3200 to $3300 \mathrm{~m}$ MD in Malm Zeta 2 (zone 3 in Fig. 6). By comparison with sonic-log measurements, both zones correlate to an increase of porosity. Further down, the spinner signal becomes unstable. In this part, a slight step in the flowmeter temperature profile indicates an additional zone (questionable zone below $3600 \mathrm{~m}$ in Fig. 6).

\section{Initial temperature log from DTS}

From the start of FO-measurements in November 2019 to the end of January 2020 (prior to the start of injection testing), the $P / T$ gauge and DTS data show that the well has not reached thermal equilibrium (see Fig. 7b). The temperature increase in that period 


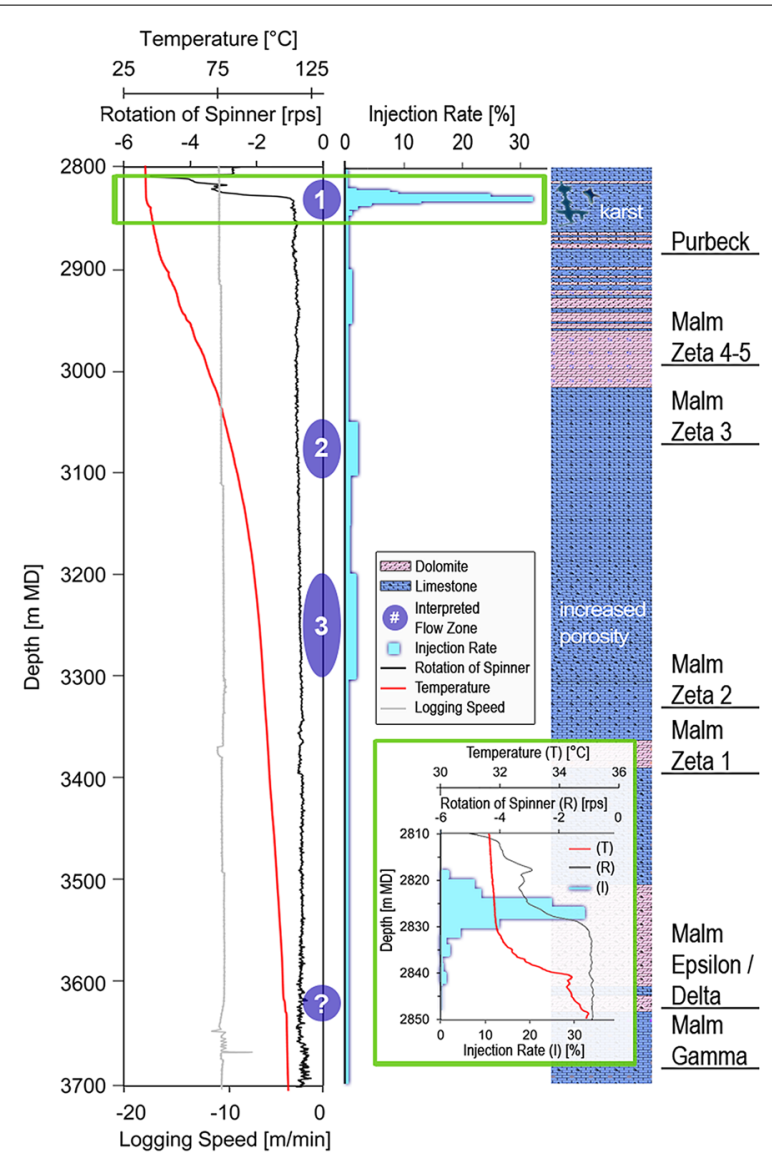

Fig. 6 Interpreted flow zones in producer well together with flowmeter spinner data, temperature and logging speed, lithology and stratigraphic units. Zoom to top section is shown in green framed box

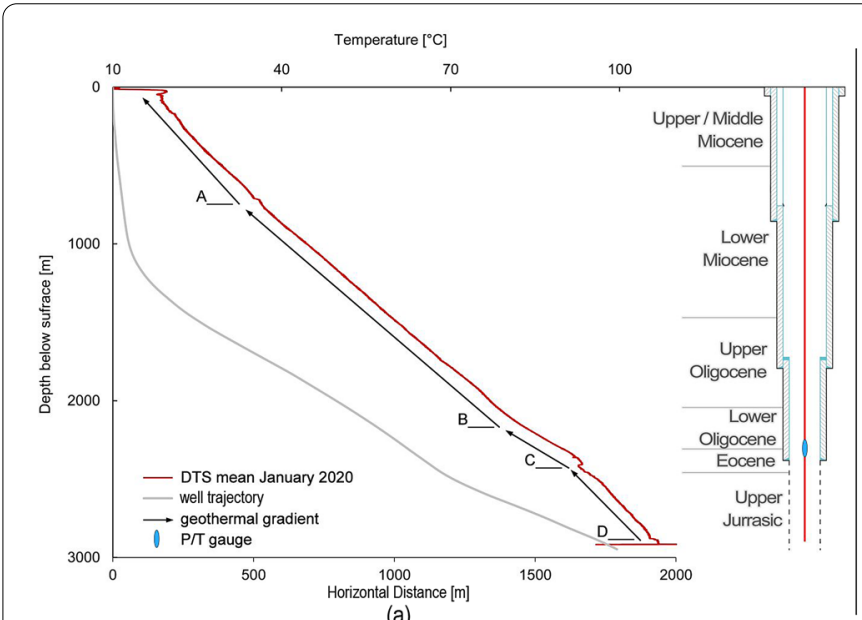

(a)

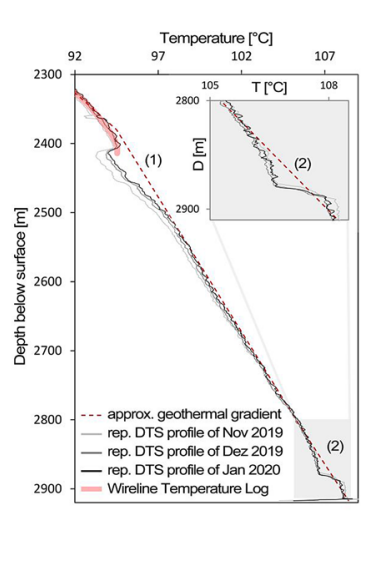

(b)

Fig. 7 Temperature gradients from DTS profile at the geothermal Schäftlarnstraße site. Subplot a shows estimated temperature gradients with vertically projected well trajectory and stratigraphy. Subplot $\mathbf{b}$ shows representative (rep.) DTS profiles from November 2019 to January 2020 averaged at over $6 \mathrm{~h}$ and with a moving average of $2 \mathrm{~m}$ with the wireline temperature log and the approximate thermal gradient inside the reservoir. (1) and (2) mark zones where the DTS temperature deviates from the proposed gradient 
extended from 0.15 to $0.2 \mathrm{~K}$ for the complete reservoir section except for a $100 \mathrm{~m} \mathrm{sec}$ tion in the upper part of the reservoir at $2500 \mathrm{~m}$ (TVD) that has heated up by about $0.35 \mathrm{~K}$. Above the reservoir section, changes in temperature profile throughout November were less than $0.5 \mathrm{~K}$, and no or very little (lower than detection limit of DTS) changes were observed in January. To create a representative continuous temperature profile with low data noise from which temperature gradients can be derived, all DTS profiles from January 2020 were taken as mean values. Figure 7a shows this profile together with the thermal gradients, approximated from the averaged DTS profile for specific depth regions (labeled A, B, C and D in Fig. 7a) showing a constant gradient. The mean geothermal gradient is $3.3 \mathrm{~K} / 100 \mathrm{~m}$, $\mathrm{A}$ is $2.7 \mathrm{~K} / 100 \mathrm{~m}$, $\mathrm{B}$ is $3.2 \mathrm{~K} / 100 \mathrm{~m}, \mathrm{C}$ is $4.7 \mathrm{~K} / 100 \mathrm{~m}$ and reservoir gradient $\mathrm{D}$ is $2.6 \mathrm{~K} / 100 \mathrm{~m}$. Furthermore, we can see some anomalies in the otherwise smooth course of the DTS profile. At point A in Fig. 7a, there is a sudden step in temperature of about $1 \mathrm{~K}$ from 710 to $720 \mathrm{~m}$. Two other deviations from the assumed geothermal gradient are in the reservoir section (referred to as zone (1) and (2) in Fig. 7b).

The first deviation (zone 1 in Fig. 7b) is in the upper $100 \mathrm{~m}$ of the reservoir between $2815 \mathrm{~m} \mathrm{MD}$ (2405 m TVD) and $2885 \mathrm{~m} \mathrm{MD} \mathrm{(2460} \mathrm{m} \mathrm{TVD)} \mathrm{and} \mathrm{deviates} \mathrm{with} \Delta T=1.2 \mathrm{~K}$ from the assumed thermal gradient. The second deviation (zone (2) in Fig. 7b) is below $3600 \mathrm{~m} \mathrm{MD}$ (2850 m TVD) and is also present in the flowmeter temperature log at the level of Malm Gamma (see questionable zone in Fig. 6). It deviates with $\Delta T=0.8 \mathrm{~K}$ from the assumed thermal gradient. Zone 2 in Fig. 7b shows little thermal dynamics, as in contrast to zone 1 , for which $\Delta \mathrm{T}$ decreases from November 2019 to January 2020, $\Delta \mathrm{T}$ of (2) is remaining constant (see gray box in Fig. 7b).

\section{FO-sensing during injection tests}

The two injection tests Inj1 and Inj2 were performed with the same duration (24 h). Inj2 differs from Inj1 in terms of a higher flow rate $(23 \mathrm{l} / \mathrm{s}$ in comparison to $16 \mathrm{l} / \mathrm{s}$ for Inj1) and a short shut-in time (28 days in comparison to more than 6 months for Inj1) as shown in Fig. 4.

\section{Acoustic sensing}

Significant DAS signals were recorded immediately after the start of testing. Figure 8 shows temporally integrated DAS strain rate data for the first minutes of both injection tests. At the very beginning of the tests ( $1 \mathrm{~min}$ after the start of injection), deep regions of the well are not yet affected by the cold water, as we find almost no acoustic response along the rods. For Inj1, the strain between 2000 and $2800 \mathrm{~m}$ is about $-1 \mu \varepsilon$ (see Fig. 8a), while no significant strain is observed for Inj2 (see blue line in Fig. 8b). Along the first $200 \mathrm{~m}$, the water is freefalling until it encounters the water table. Here, the rods are cooled by the injected water. At $750-800 \mathrm{~m}$, a step of 0 to $-1 \mu \varepsilon$ for Inj2 at $+1.5 \mathrm{~min}$ and -0.5 to $-3 \mu \varepsilon$ for Inj1 at $+3 \mathrm{~min}$ is evident. A second step is at $1900-2000 \mathrm{~m}(-0.5$ to $-2 \mu \varepsilon$ for Inj2 at $+1.5 \mathrm{~min})$. Both steps are at the location of the $133 / 8$-in. hanger (770 $\mathrm{m})$ and 9 5/8-in. hanger $(1907 \mathrm{~m})$, respectively. A third step can be found at 2800 $2850 \mathrm{~m}$ with local high negative and positive strain rates for Inj2 ( -10 to $20 \mu \varepsilon$ ). From 2850 to TD at $3700 \mathrm{~m}$, the strain is zero. The stepwise change of the strain rate from 250 to $2800 \mathrm{~m}$ can be interpreted with respect to the well completion. As the inner diameter 


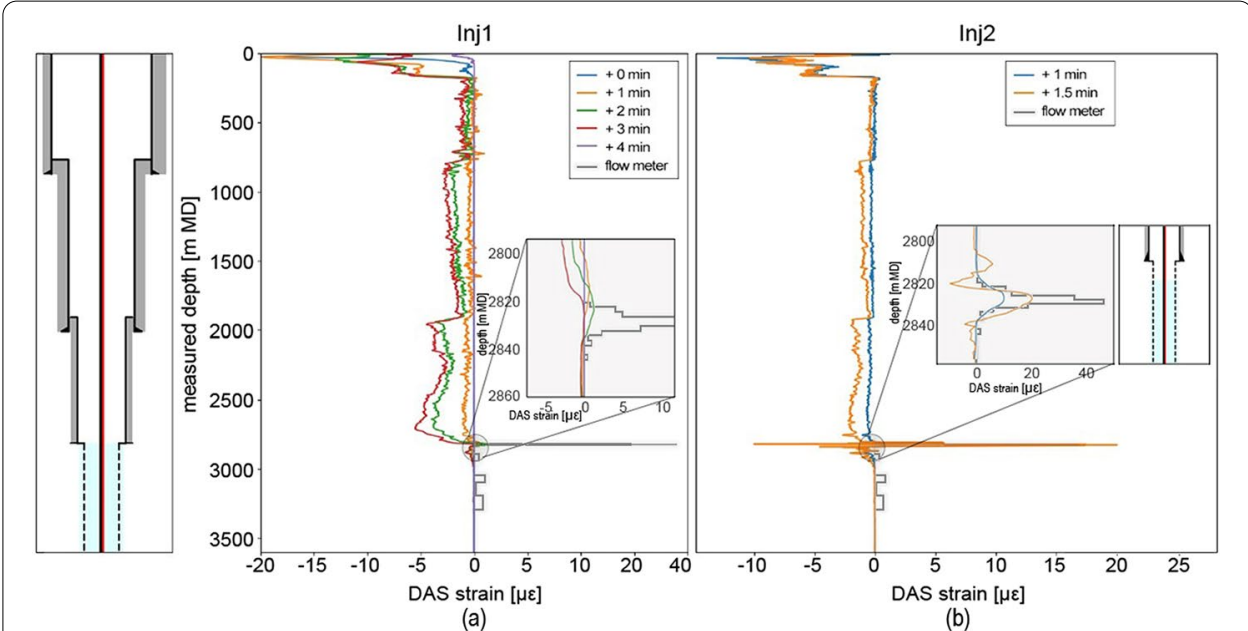

Fig. 8 DAS strain measurements at the beginning of injection tests Inj1 (a) and Inj2 (b). The gray line marks the injection profile from flowmeter. DAS strain at the top of the reservoir is given in zoomed in sub plots

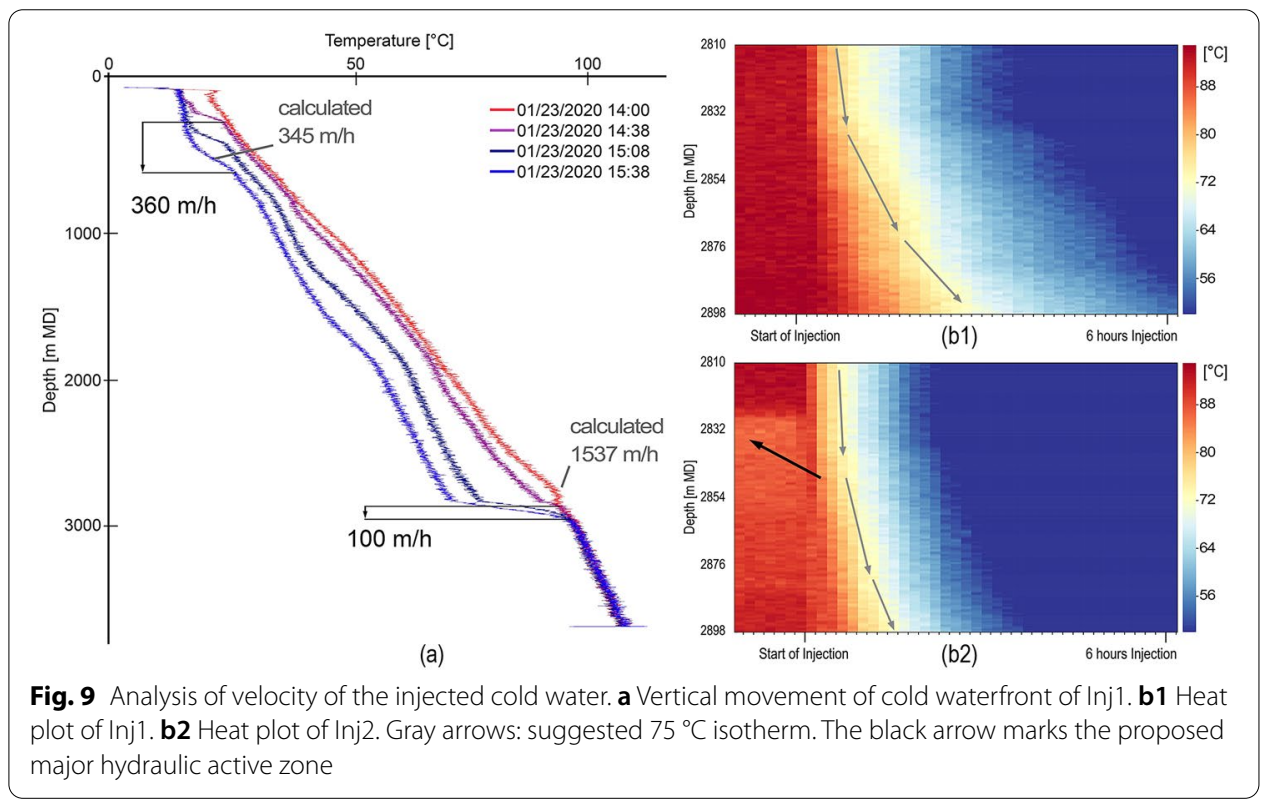

decreases at the liner hanger, flow velocity rises and the volume of water per meter depth decreases, which means a higher cooling rate.

\section{Temperature sensing during cold water injection tests}

The DTS profiles recorded during the injection tests (one every $10 \mathrm{~min}$ ) were used to estimate the water flow velocities inside the well. Figure 9a shows how the thermal front of the injected water of Inj1 (analogous plot for Inj2 is attached in Additional file 3) moved vertically down the well. In the first section, velocity of the thermal front is of about $360 \mathrm{~m} / \mathrm{h}$, when the calculated theoretical velocity (see Eq. 2) at an injection rate of $16 \mathrm{l} / \mathrm{s}$ is $345 \mathrm{~m} / \mathrm{h}$. At top of the slotted 7-in. liner, the calculated velocity is $1537 \mathrm{~m} / \mathrm{h}$. 


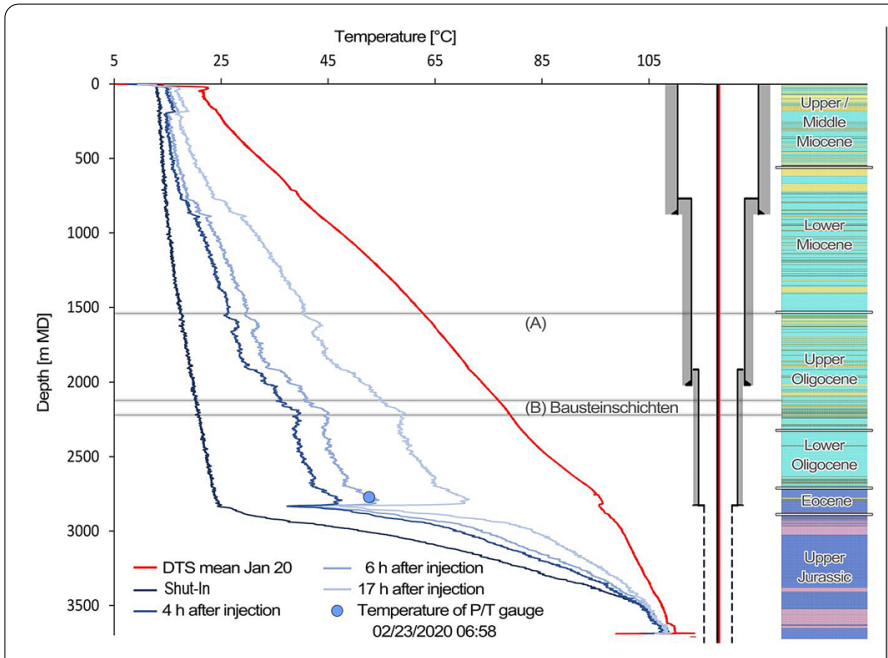

(a)

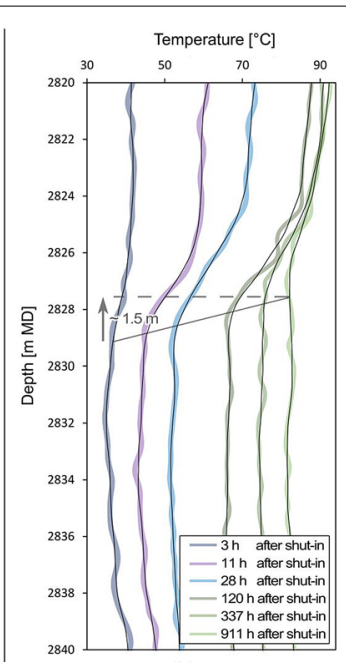

(b)

Fig. 10 DTS profiles during warm-back of Inj2. a Warm-back profiles at 4, 6 and $17 \mathrm{~h}$ after shut-in together with the mean profile of January 2020 and the Shut-In profile over whole borehole in comparison to stratigraphic units and the well completion. $\mathbf{b}$ DTS peaks during long-term warm-back at top of the reservoir from $2810 \mathrm{~m}$ MD to $2840 \mathrm{~m}$ MD. The bold curves are raw DTS data, fine black curves are moving average over $2 \mathrm{~m}$. The gray line indicates a vertical shift of about $1.5 \mathrm{~m}$

Right on top of the reservoir section, we can see a slowdown of the cold front, indicating that the majority of injected water got lost to the formation. The vertical movement of the cold front is then about $100 \mathrm{~m} / \mathrm{h}$.

Roughly estimated from the velocity change and by applying Eq. 3, we can assume that the zone took up about $93.5 \%$ of the water. For Inj2 the percentage inflow is accordingly calculated to $94 \%$ (see Additional file 3).

Figure $9 \mathrm{~b} 1$ and $\mathrm{b} 2$ shows the temperature DTS injection profiles in the upper reservoir section from $2810 \mathrm{~m}$ MD to $2898 \mathrm{~m}$ MD for both tests. Since the flow rate of Inj1 was lower than for Inj2, the movement of the cold front was much slower, which is why the heat plots show a higher gradient for Inj2 than for Inj1. It took about $6 \mathrm{~h}$ of injection for Inj1 to cool by $40{ }^{\circ} \mathrm{C}$ at $2898 \mathrm{~m} \mathrm{MD}$; this happened twice as fast for Inj2 due to the larger amount of flowing cold water. In both cases, we see near-vertical isotherms to a depth of $2830 \mathrm{~m} \mathrm{MD}$, below the slope changes, indicating that the formation took the injected water at this location. Furthermore, we can recognize a colder region at Inj2 (indicated by brighter color in Fig. 9b2) before the start of injection, beginning at $2827 \mathrm{~m}$ MD that fades out below. This is due to the cold water the formation took up when Inj1 was performed. For Inj1, the temperature deviation is much smaller $(\Delta T=1.2 \mathrm{~K}$, see Fig. 7) because the shut-in time was large ( $>6$ months) and the fluid was able to warm towards the formation temperature.

\section{DTS during warm-back}

As the well was shut-in, the water in the wellbore began to heat up back to the undisturbed formation temperature. Figure 10a depicts DTS profiles during the warm-back after Inj2 (see Additional file 4 for Inj1) at different time stamps (4, 6, $17 \mathrm{~h}$ after shutin) together with DTS at shut-in and the mean DTS profile of January 2020. Interesting 


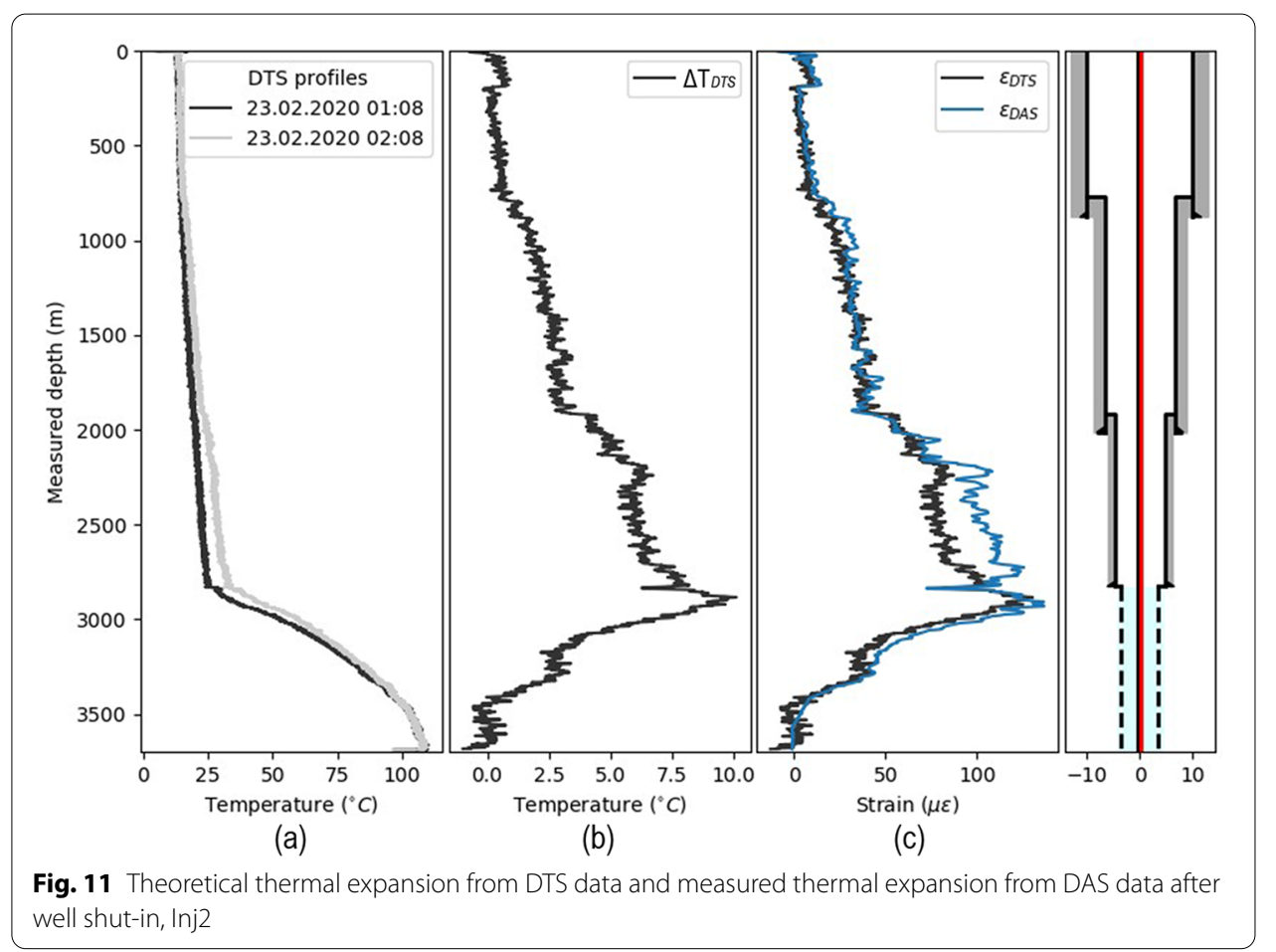

steps and changes are present in the warm-back profiles. One is located in $200 \mathrm{~m}$ depth that divides a strong uniformly heating section above from a less strong heating below. A second one is between 750 and $900 \mathrm{~m}$, a third one at around $1500 \mathrm{~m}$ [marker (A) in Fig. 10a], a fourth one at $2135 \mathrm{~m}$ [marker (B) in Fig. 10b] and another one at the top of the reservoir. Warm-back profiles in the Upper/Middle Miocene, the Lower Miocene and the Lower Oligocene are relatively uniform, while the profiles in the Upper Oligocene showing higher variation. Below $2380 \mathrm{~m}$, with beginning of the reservoir section, warm-back profiles change significantly. Throughout the profiling a slower warm-back was recorded at $2830 \mathrm{~m} \mathrm{MD}$, followed by a sharp increase of slope of the DTS profiles below. For long shut-in times, we noticed a vertical shift of the temperature profiles of about $1.5 \mathrm{~m}$ compared to the injection profile (see gray shift line in Fig. 10b).

\section{Thermal contraction}

DAS was used to evaluate whether the vertical shift in the data (see gray line in Fig. 10b) was caused by a thermal expansion or contraction of the sucker rod/TEF structure during the warm-back process. Figure 11a shows two DTS profiles, one during shut-in and one $60 \mathrm{~min}$ after shut-in of Inj2. Figure 11b demonstrates the temperature difference between these two profiles. The third subplot (Fig. 11c) shows the theoretical expansion of the fiber/cable/sucker rod due to heating, calculated with Eq. 1 and the DAS strain rate, integrated over the same 60 -min period. A clear match is visible between the calculated theoretical thermal expansion from DTS data $\varepsilon_{\text {DTS }}$ and the actual measured expansion from DAS data $\varepsilon_{\mathrm{DAS}}$. In the depth interval from 2200 to $2800 \mathrm{~m}$ a larger expansion (up to $25 \mu \varepsilon$ ) was measured from DAS than would be expected from $\varepsilon_{\mathrm{DTS}}$. 


\section{Discussion}

After the successful implementation in the deviated production well, the FO-monitoring period during shut-in and the two injection tests showed that reservoir characterization and detailed correlation and comparison with other measurement devices can successfully be conducted. However, the results of the FO-system need to be evaluated in terms of the mechanical dynamics of the system design along the sucker rod structure.

\section{Dynamic temperature development in the monitored well}

The 3-month shut-in monitored by DTS (November 2019, installation of the FO-system to end of January 2020, start of the first cold water injection test) showed that the well had not yet reached thermal equilibrium in this period (see Fig. 7b). However, dynamic zones that were still warming up were found mainly in the reservoir section. There was little heating in the cased sections of the well in November and no noticeably heating, respectively, heating lower than the detection limit of DTS in January. Thus, we assume that DTS profiles of January are close to the geothermal gradient, apart from the dynamic zones within the reservoir section. The graphically derived mean geothermal gradient is $3.3 \mathrm{~K} / 100 \mathrm{~m}$, which is a typical value for the Bavarian Molasse Basin (Bauer and Freeden 2014). A more detailed analysis revealed four different thermal gradients, labeled A, B, C and D in Fig. 7a. Up to $800 \mathrm{~m}$, gradient A is $2.7 \mathrm{~K} / 100 \mathrm{~m}$, which is also typical for the Southern Molasse Basin (Casper et al. 2014; GeoMol Team 2015). Second, $\mathrm{B}$ is higher at $3.2 \mathrm{~K} / 199 \mathrm{~m}$ down to $2000 \mathrm{~m}$ depth, near the boundary between the layers of the Upper and Lower Oligocene. Third, $\mathrm{C}$ up to top reservoir is the highest gradient with $4.7 \mathrm{~K} / 100 \mathrm{~m}$ and lastly $2.6 \mathrm{~K} / 100 \mathrm{~m}$ for the reservoir section itself. Assuming a constant heat flow, according to Fourier's law, a high gradient indicates low thermal conductivity of the rock (e.g., Eppelbaum et al. 2014; Zarrouk and McLean 2019), which means that the most prominent gradient $(\mathrm{C})$ is due to the low thermal conductivity of the shaly Rupel rock of the Lower Oligocene that is delimited from the sandy Chatt rock of the Upper Oligocene. For example, Homuth (2014) proposed thermal conductivities of about $2.53 \mathrm{~W} /(\mathrm{mK})$ for Rupel rock and up to $3.15 \mathrm{~W} /(\mathrm{mK})$ for Chatt rock.

The two cold water injection tests, Inj1 and Inj2, ended the shut-in period after FOconstruction. We artificially disturbed the nearly equilibrated temperature distribution inside the well and measured the warm-back to initial conditions. For both Inj1 (see Additional file 4) and Inj2 (see Fig. 10a), we saw that the uppermost $200 \mathrm{~m}$ in the well heated more rapidly than those below. $200 \mathrm{~m}$ is about the expected depth of the water table. Up to this depth, the TEF mounted on the sucker rods is likely hanging in the middle of the borehole, with no contact to the casing. Here, the cable is surrounded by air with a lower heat capacity of about $1.0 \mathrm{~kJ} /(\mathrm{kgK})$. Thus, the cable heated much faster than below, where the ambient medium is water, having a heat capacity at $20^{\circ} \mathrm{C}$ of about $4.2 \mathrm{~kJ} /(\mathrm{kgK})$. Irregularities in the warm-back profiles were found at the top liner hanger of the anchor tubing $(750 \mathrm{~m})$. It is likely that the combined effects of cementing and casing of the liner hanger affected the heat transfer here. From $900 \mathrm{~m}$ to about $1500 \mathrm{~m}$, a uniform heating behavior can be seen when getting through the layers of the shaly Lower Miocene. At the change of the shalier Lower Miocene to the sandier Upper Oligocene, there is a notable temperature drop in the warm-back profiles. Here (marker A in Fig. 10a), we find a 50-m-thick clay marl layer that might act as a hydraulic barrier or 
indicate a local lower thermal conductivity of the rock. The Upper Oligocene reaches to a depth of about $2330 \mathrm{~m}$ (2050 m TVD) and shows to be more heterogeneous than the layers above. This is also reflected by the warm-back DTS profiles as they increase in variance. Notable is a sudden temperature step at $2135 \mathrm{~m}$ (1960 m TVD), which is on the horizon of the Bausteinschichten (marker B in Fig. 10a). Below this is a 70-m-thick layer of clay marl with less heating. From 2330 to $2710 \mathrm{~m}$ we see uniform heating in the shaly Rupel layers of the Lower Oligocene. Koch et al. (2006) studied samples from 14 wells of the Molasse basin and found that thermal conductivity of the Bausteinschichten ranges from $1.57 \mathrm{~W} /(\mathrm{mK})$ to $3.81 \mathrm{~W} /(\mathrm{mK})$ with a mean of $2.88 \mathrm{~W} /(\mathrm{mK})$. The Rupel formation has lower mean thermal conductivities, e.g., Homuth (2014) gave a value of $2.53 \mathrm{~W} /$ $(\mathrm{mK})$, and shows to have a thermal insulation effect during warm-back.

\section{Construction and design issues}

\section{FO-installation}

Running logging tools in highly deviated wells is challenging. At the study site, this was shown when a conventional wireline temperature log could not pass the 7-in. liner hanger. The design of the downhole FO-construction was focussed on minimizing this risk. The installation along sucker rods to the reservoir was successful. However, the design of the FO-system posed challenges in both the installation and the analysis of the FO-measurements. Installation was performed with a triple drilling rig. Designed for heavy weights, no significant hook load could be recorded on the driller's console because of the low weight of the sucker rods. As the fiber optic rotary joint was noisy (see Ch. 2.2), checking the integrity of the sucker rod string during installation turned out to be challenging. The final installation showed losses at the wellhead splices and connectors, at the splice at the $P / T$ gauge and at the mini-bend. Apart from those, no unexpected anomaly in the attenuation profile occurred. The combined losses were however demanding for the daisy-chained DAS measurements across both wells, mainly due to the relatively high loss at the mini-bend in the injector well.

\section{DTS anomaly}

First DTS measurements after installation showed a temperature anomaly inside the borehole that is a $1 \mathrm{~K}$ temperature step above the transition of section 1 to section 2 from 710 to $720 \mathrm{~m}$ (see Fig. 7a). This is about $50 \mathrm{~m}$ above the liner hanger and can be found in every DTS profile recorded before Inj1 (November 2019 to end of January 2020). The anomaly disappeared with Inj1 and cannot observed in DTS profiles recorded afterwards. Figure 12 shows the mean DTS profile from January 2020, the wireline temperature log and three exemplary profiles that were recorded before and after Inj1. As neither the independent wireline temperature log does show a similar anomaly, nor is there evidence of bad cementing or other influences, e.g., a rock layer with little thermal conductivity (Wisian et al. 1998), it is obvious that the temperature step might relate to the FO-installation. OTDR measurements do not show suspicious loss in the respective depth that would indicate a damage of the fibers. One hypothesis is that the DTS temperature step reflects a stratification of the water column, possibly triggered by the pulling of the 13 3/8 inch tieback, which happened immediately prior to FO-installation (see Ch. 2.2). The tieback was initially placed after cementing the second section of the well 


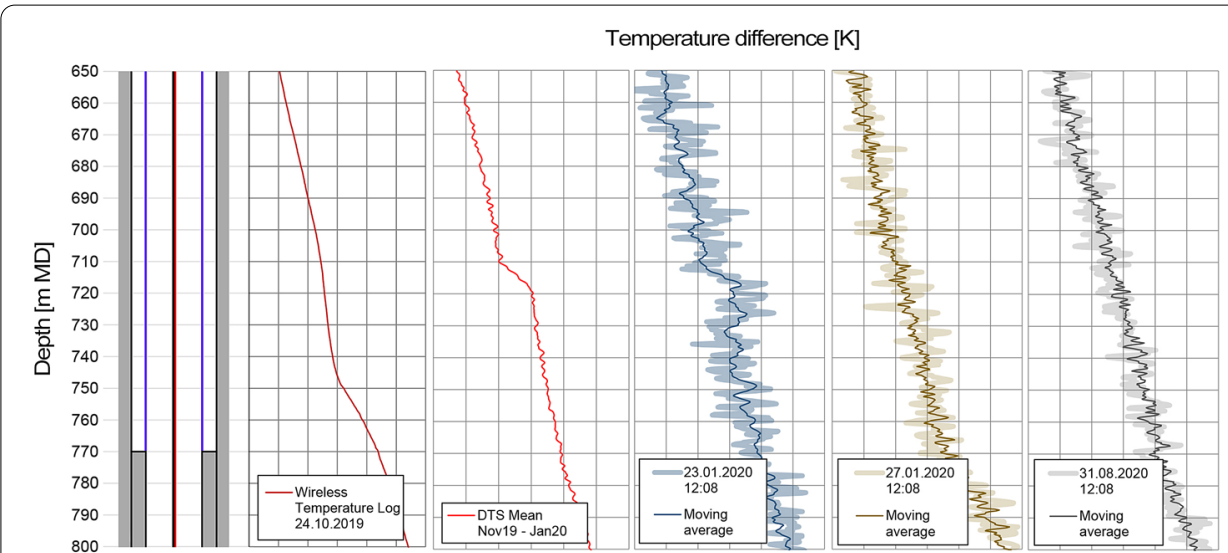

Fig. 12 Changing of temperature profiles over time in the first section. First subplot to the left shows the completion with tieback liner in blue and TEF/sucker rod in red. Second subplot shows the wireline temperature log that was recorded inside the tieback liner. Third to sixth subplots show DTS profiles that were recorded in the borehole as the tieback liner was pulled. Third subplot is the mean DTS profile until start of Inj1, fourth shows a DTS profile shortly before start of Inj1, fifth is 3 days after Inj1, sixth subplot shows a current DTS profile. Transparent lines are raw DTS data, sharp lines are moving average over $4 \mathrm{~h}$ at a spatial resolution of $2 \mathrm{~m}$

and the following purging. Thus, the drilling mud remaining in the annulus, behind the tieback, would not be mixed with the short-term airlift production tests that were performed with the installed tieback after well completion. With pulling the tieback, mud residues might accumulated at 710 to $720 \mathrm{~m}$, which might cause an insulation effect and a thermal stratification.

\section{Depth displacement}

One challenge of the sucker rod construction for permanent monitoring might be its dynamic behavior. The two injection tests carried out in January and February 2020 indicated that temperature changes cause thermal contraction and expansion of the sucker $\mathrm{rod} /$ fiber cable installation (Figs. 10b and 11c) along with a vertical shift of the fibers and the $P / T$ gauge. Such behavior is well known, for example, for conventional wireline measurements (Grant and Bixley 2011; Zarrouk and McLean 2019).

Depth calibration is essential for interpreting DTS values (e.g., Smolen and Spek 2003). Therefore, different temperature profiles require their own post-processing to correctly assign measured temperatures. As a consequence, all of the DTS and DAS profiles of the cold water injection tests shown in this study have a slightly incorrect depth assignment since the depth calibration refers to the less disturbed temperature profile as it was after FO-installation. The relevance of the displaced $P / T$ and DTS measurements can be estimated by calculating the theoretical displacement of each measurement point along the downhole FO-construction caused by the thermal contraction related to the cold water injection. According to, e.g., Zarrouk and McLean (2019) this is given by Eq. 4:

$$
\Delta L=\int_{x_{1}}^{x_{2}} \Delta T_{\mathrm{DTS}}(x) * \alpha_{\mathrm{th}} * \mathrm{~d} x,
$$




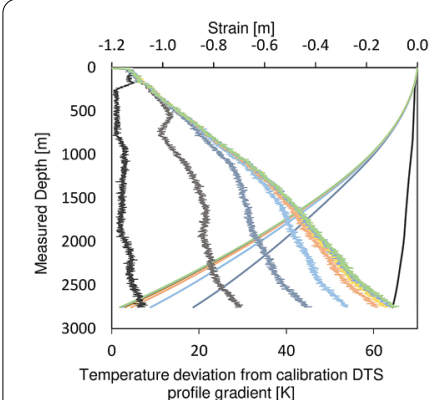

(a)

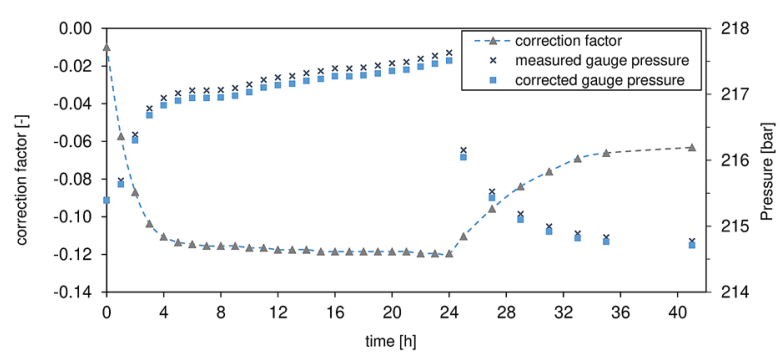

(b)

Fig. 13 Calculated strain from DTS and corrected pressure data. a Calculated strain from DTS data to the depth of the P/T gauge in the first $7 \mathrm{~h}$ of injection of Inj2. Curves on the left $\mathrm{y}$-axis are temperature deviations from the initial DTS profile. Curves on the right $y$-axis are the resulting strain for each DTS profile. b Measured gauge pressure data with correction factor to revise thermal caused displacement

where $\Delta L(\mathrm{~m})$ is the expansion length due to the temperature deviation $\Delta T_{\mathrm{DTS}}(\mathrm{K})$ of a DTS injection profile from the undisturbed DTS profile, $x(\mathrm{~m})$ is the respective depth and $\alpha_{\mathrm{th}}\left(\frac{1}{\mathrm{~K}}\right)$ is the thermal expansion coefficient for the construction, that again is assumed to $13^{-6} \mathrm{~K}^{-1}$ (see Ch. 2.6). The maximum calculated displacement at the end of the construction is about $1.5 \mathrm{~m}$ for both Inj1 and Inj2. Such a scale does not play a major role for DTS, considering that depth assignment and the exact location of TD are subject to a certain error, as for example the accuracy of drillers tally, as well as the fact that the downhole temperature does generally not change rapidly at the scale of few meters, which is also shown by the common geothermal gradient of $0.033 \mathrm{~K} / \mathrm{m}$ in the Bavarian Molasse Basin (e.g., Bauer and Freeden 2014; Casper et al. 2014 and proposed thermal gradient in Fig. 7a).

The calculated displacement of the $P / T$ gauge at $2755 \mathrm{~m} \mathrm{MD}$ is shown in Fig. 13 for the first $7 \mathrm{~h}$ of the injection period of Inj2. After $4 \mathrm{~h}$ of injecting, temperature profiles and the resulting thermal stress change only very slightly. The vertical displacement is around $1.2 \mathrm{~m}$ to the end of Inj2. The pressure at the correct position of the $P / T$ gauge can be recalculated by applying a correction factor to the measured gauge pressure:

$$
\Delta p=\rho * 9.81 \frac{m}{s^{2}} * \Delta h
$$

where $\Delta p$ (bar) is the hydrostatic pressure of the water column between the correct and the dislocated gauge with height $\Delta h(\mathrm{~m})$ (vertical displacement) and $\rho\left(\frac{\mathrm{kg}}{\mathrm{m}^{3}}\right)$, the density of water column in the well. The density of the fluid of the water column was assumed to be $1005 \mathrm{~m}^{3} / \mathrm{kg}$ in accordance with Eppelbaum (2014), who reported values for water at $25 \mathrm{MPa}$ and $25^{\circ} \mathrm{C}$, which approximates the conditions at the respective depths during cold water injection. At the beginning of the injection test, the correction factor $\Delta p$ is low, but after the borehole was cooled down almost completely ( $4 \mathrm{~h}$ of injection), the calculated measurement deviation is about -0.12 bar.

Initial $P / T$ gauge pressure before Inj2 was $215.1 \mathrm{bar}$. The pressure increase throughout the test was 2.5 bar and the maximum recorded pressure was 217.6 bar at shut-in. With maximum deviation of 0.12 bar due to the displacement, the resulting error of pressure increase is therefore $5 \%$. 
Consequently, the FO depth calibration should be reconsidered when the well starts to produce, because this will cause a different temperature profile inside the well to be recorded. Up to now, DTS is calibrated with respect to the temperature profile after FOinstallation that shows little heating apart from the hydraulic active zone (see Fig. 7). In production, the thermal stresses in the reservoir will not play as large a role as in the injection tests performed.

The top sucker rod will be located below the ESP, thus most of the sucker rods in the top section will be replaced by the production tubing. Subsequently, the sucker rod string will be shortened by around 700 to $800 \mathrm{~m}$. Additionally, temperature gradients between production temperature and shut-in temperature in the reservoir will be lower, and thus the thermal stress at the sucker rods in the reservoir will be less than during the injection tests. A similar FO-installation design in injection wells should consider relevant temperature changes and subsequent displacements.

Open questions remain concerning the excess of about $25 \mu \varepsilon\left(\varepsilon_{\text {DAS }}\right)$ over the theoretical expansion $\left(\varepsilon_{\text {DTS }}\right)$ between 2200 and $2800 \mathrm{~m}$ (see Fig. 11c). The excess may be due to the fact that $\varepsilon_{\mathrm{DTS}}$ only relates to the time period between two DTS profiles, while the strain evolution during temperature changes also includes information from previous events. For example, the initial stresses 'stored' inside the rod may not exceed frictional forces and are therefore not measured by DAS. Another possible error-proneness of the method lies in the nature of the procedure for generating DTS data in our system. The timestamp of a DTS profile is set to the end of one measurement, which means that the profile can be understood as an averaging temperature over the last $10 \mathrm{~min}$. The well was shut at 23.02.2020 00:56, the first DTS profile of the considered 60-min period was recorded at 01:08. Consequently, the sucker rod/TEF construction has already been subject to warm-back and thermal expansion. Cumulative strain $\varepsilon_{\mathrm{DAS}}$ covers exactly the 60-min period from 01:08 to 02:08, although the comparison of $\varepsilon_{\text {DAS }}$ and $\varepsilon_{\text {DTS }}$ is liable to shift. Further research about the relation of measured DTS and DAS data to friction forces inside the well is discussed in Lipus et al. (2021).

The consequence of the above findings is that all DTS profiles of the injection tests have a shift in depth due to thermal contraction. However, the vertical displacement at the top of the reservoir (near to the $P / T$ gauge at $2755 \mathrm{~m} \mathrm{MD}$ ) is no more than $1.2 \mathrm{~m}$, which is about the $1 \mathrm{~m}$ spatial resolution of the processed DTS data (see Ch. 2.3). This is a small magnitude relative to the distance over which significant temperature changes take place (e.g., major flowmeter zone that flowmeter data showed over a distance of $15 \mathrm{~m})$.

\section{Reservoir characterization}

While monitoring the temperature in the reservoir section showed high dynamics of the thermal distribution over the reservoir section, the questionable zone near TD at $3630 \mathrm{~m}$ MD (see Figs. 6 and 7b) was unaffected by the hydraulic tests. Here, all available temperature profiles (flowmeter temperature and DTS before, during and after injection tests) show a temperature anomaly with little dynamic behavior (see Fig. 7b). The fact that this is also present in the measurements that are independent from DTS (flowmeter) shows that the anomaly is not a FO-system design-related factor. The observed anomaly can either be interpreted as minor hydraulically active zone, in form of a fault 
zone (that is unclear from geological model) or as insulation effect from drilling residues (drill fluid, ingress of material, sludge) that accumulated at the bottom hole (Zarrouk and McLean 2019). As there is no evidence for either of the two hypotheses up to now, no reliable interpretation can be made. The origin of the anomaly can be clarified when the well produces.

To localize hydraulic active zones, flowmeter analyses were compared with DTS and DAS data. Flowmeter is the preferred tool for locating flow zones inside the reservoir. However, interpreting flowmeter measurements in highly deviated wells with perforated liner is difficult (e.g., Haoua et al. 2015), as flow regimes become more complex than for vertical wells and fluid velocity behind the liner tends to change apparently without context to feed zones (Zarrouk and McLean, 2019). In this study, both are present (deviation of $58^{\circ}$ in the reservoir section and perforated 7-in. liner). Additionally, the most prominent flowmeter response (92\% interpreted inflow, see Fig. 6) was at the very top of the reservoir section from 2820 to $2838 \mathrm{~m} \mathrm{MD}$, where flow might have been disturbed due to turbulence of the narrowing of the diameter at the transition of section 3 to the perforated liner. Minor flow zones were interpreted below where there is an increase of porosity of the formation (see Fig. 6).

The cold water injection experiments were performed to test the newly installed FO-system and to confirm the flowmeter interpretation. Assumed flow velocities from thermal front movement from DTS (see Fig. 9a) confirm flowmeter results by giving a percentage inflow of $93.5 \%$ (Inj1), respective $94 \%$ (Inj2) at $2830 \mathrm{~m} \mathrm{MD}$. This is in accordance with the inflows interpreted from flowmeter (92\%). Further down in the reservoir section, no vertical movement is evident in the DTS profiles, indicating that the injected water was lost above, or that fluid flow velocities were below the detection limit of the DTS analysis. Ali et al. (2013) also used fluid velocity analysis when they monitored DTS during an injection of water to the carbonatic reservoir of a test well in the south-west of the USA. Similarly to the Schäftlarntraße well considered in our study, the major feed zone they investigated was a highly permeable karstic zone. They found that increasing the injection rate resulted in a relatively higher contribution from the karstified zone-likely due to non-linear pressure losses at the feedzone or the opening of fractures - and a relatively lower contribution from the minor feed zones. A similar behavior cannot be indicated for our tests, but this may be due to the dominance of the main inflow zone, which contributes with $92 \%$ (flowmeter), respectively, 94\% (velocity analysis of Inj2). Figure 14 summarizes the results of flowmeter interpretation (Fig. 6) and FO-measurements during the injection period of Inj2 (Figs. 8b and 10). During the analyses of the DAS data (Fig. 8), we found that the strain profiles tend to negative values with progressing time, thus cooling of the well. However, shortly after beginning of the injection test Inj2 $(+1 \mathrm{~min})$, a positive DAS strain is seen at 2820 to $2840 \mathrm{~m}$ that agrees very well with the flowmeter inflow profile. For this profile, we can see close to $0 \mu \varepsilon$ above or below the active zone, except for the uppermost $200 \mathrm{~m}$ where the water was freefalling until it hit the water table (see Fig. 8). We assume that there was no or very little thermal or mechanical effect on the sucker rod/downhole cable at this time. Hence, the local DAS signal at the hydraulically active zone cannot be interpreted as positive strain (extraction of the rod), after that no heating process is conceivable here. Thus, the DAS signal indicates that fluid 


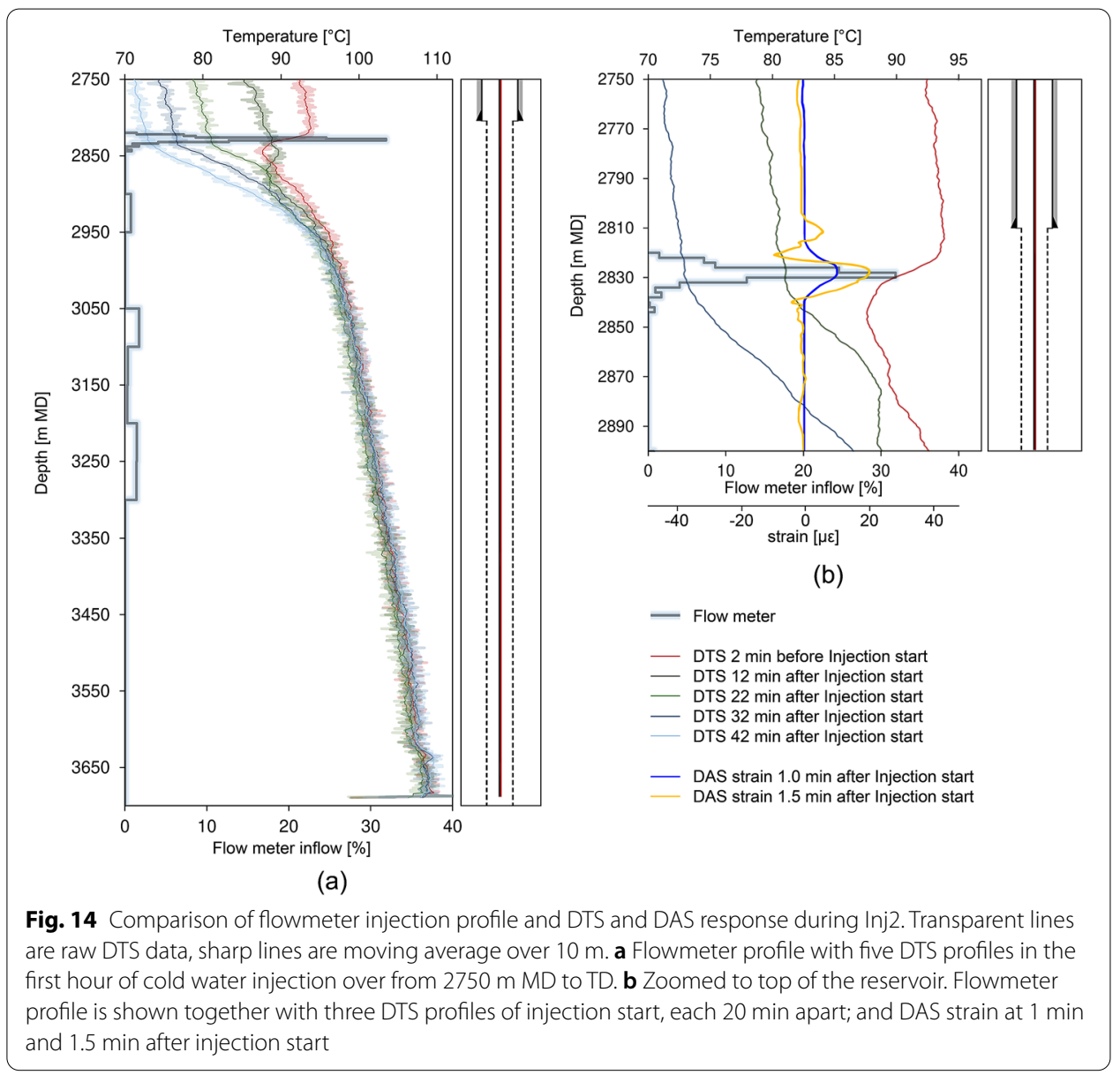

flow between borehole and reservoir rock might induced an acoustic response that was later obscured by the mechanical/thermal stress. However, this could only be observed in the first minute after injection start and only for Inj2. Figure 8 shows that there is no comparable recording for Inj1. The reason for this is unknown, however the differences from Inj1 and Inj2 in terms of flow rate (16 l/s in comparison to $23 \mathrm{l} / \mathrm{s}$ ) and shut-in time (34 weeks in comparison to 4 weeks) are obvious.

Just a little later $(+1.5 \mathrm{~min})$, strain built up and negative strain, thus contraction, was present throughout the cased sections, which is related to thermal stress (see Fig. 8). To verify whether in fact the DAS signal $+1 \mathrm{~min}$ is related to the noise of flowing fluid, a detailed description of the signal, e.g., analysis of the frequency information needs to be executed. Paleja et al. (2015) used Fourier transformation to directly evaluate flow velocities from DAS. Such is beyond the scope of this study and can be addressed in a future study. However, it is apparent that the DAS data at the hydraulically active zone at $2830 \mathrm{~m}$ MD show high dynamics. As testing time progresses, abrupt and spatially defined acoustic signals occur, mostly below $2800 \mathrm{~m}$, more rarely above from 2000 to $2800 \mathrm{~m}$. Lipus et al. (2021) referred to those as 'sucker rod events' and gave an analysis of the complete DAS dataset that was created throughout the entire injection test Inj2. DTS profiles show that the same zone took the injected cold 


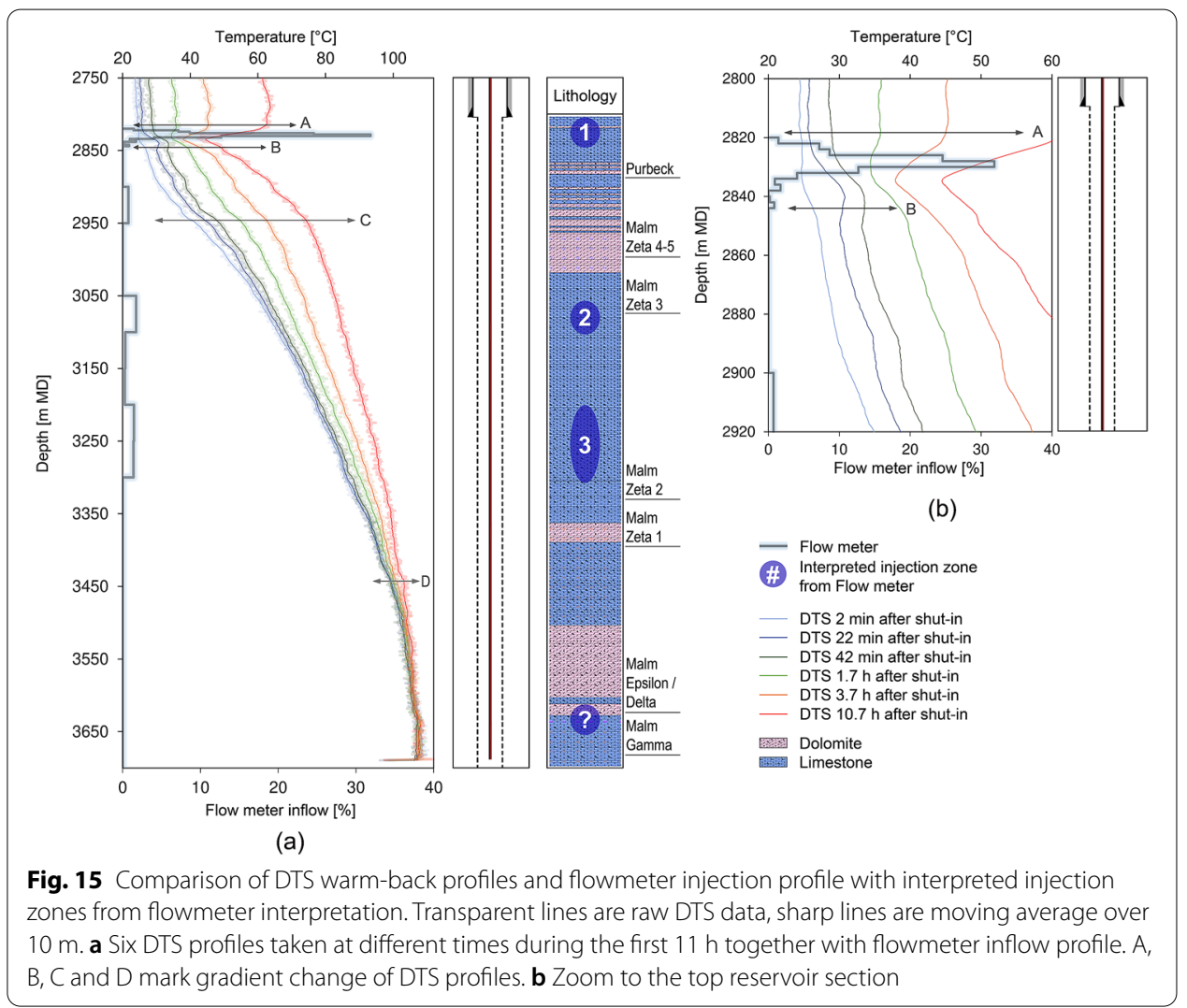

water rapidly during the first $42 \mathrm{~min}$ of injection. The inflection point of the DTS curves is at $2835 \mathrm{~m} \mathrm{MD}$, which is very near to the major contribution zone from flowmeter at $2828 \mathrm{~m}$ MD to $2830 \mathrm{~m}$ MD. Below $2835 \mathrm{~m} \mathrm{MD}$, the slope of the DTS profiles increases strongly, indicating less cooling, and below $2950 \mathrm{~m}$ MD no difference in the DTS curves of the first $42 \mathrm{~min}$ of Inj2 is present.

After $24 \mathrm{~h}$ of injection, the section from $3500 \mathrm{~m}$ MD to TD was the only one unaffected by the cold water injection. As the temperature recovers towards the undisturbed equilibrium, the transient temperature distribution gives evidence of hydraulically active zones (Henninges et al. 2005; Ali et al. 2013).

Figure 15 shows a comparison of the flowmeter injection profile (Fig. 6) with DTS profiles at irregular intervals from shut-in to $10.7 \mathrm{~h}$ after shut-in. Additionally, the interpreted injection zones of flowmeter (see Fig. 6) and interesting slope changes of warm-back profiles (A, B, C and D in Fig. 15) are shown.

Above $\mathrm{A}$, which is at $2820 \mathrm{~m} \mathrm{MD}$, heating is uniform, indicating mainly conductive heat transfer (Ali et al. 2013). From A to B there is slow heating, suggesting that most of the injected cold water infiltrated within this zone. This also strongly agrees with the observed major inflow from the flowmeter measurements (zone 1). The gradient of the DTS profiles increases towards B, which may indicate less inflow to the formation near B at $2840 \mathrm{~m}$ MD. Below B (2845 m MD to $2950 \mathrm{~m} \mathrm{MD}$ ), there is a gradient change that indicates minor inflow, most clearly visible in the first 42 min after shutin. Flowmeter did not show any evidence of such at 2845 to $2880 \mathrm{~m} \mathrm{MD}$, but a minor 
spinner response was seen at 2900 to $2950 \mathrm{~m} \mathrm{MD} \mathrm{(<1 \%} \mathrm{inflow).} \mathrm{During} \mathrm{injection,} \mathrm{an}$ inflow between B and C is not clearly evident, however some scattered DTS profiles indicate hydraulically activity at $2890 \mathrm{~m} \mathrm{MD}$ (e.g., $12 \mathrm{~min}$ and $22 \mathrm{~min}$ after injection start, see Fig. 14). Between C (2950 m MD) and D (3450 m MD), warm-back profiles are uniform and do not indicate further hydraulically active zones. At $\mathrm{D}$, a locally defined further gradient change is evident over a distance of about $10 \mathrm{~m}$, indicating minor inflows. The questionable zone at $3650 \mathrm{~m} \mathrm{MD} \mathrm{(see} \mathrm{zone} \mathrm{marked} \mathrm{with} \mathrm{question}$ mark in Fig. 6) is not represented by the warm-back profiling.

In contrast to Sakaguchi and Matsushima (2000), who found in hydraulic tests that their DTS system detected flow zones more clearly during injection than during warmback, in our case the first hours of temperature recovery indicate a hydraulically active zone between B and C (2850 m MD to $2950 \mathrm{~m} \mathrm{MD)} \mathrm{that} \mathrm{was} \mathrm{not} \mathrm{clearly} \mathrm{perceived} \mathrm{dur-}$ ing the injection period. The injection and temperature recovery profiles of the well SN-8R, Sakaguchi and Matsushima (2000) studied, suggest that the different fractures took a relatively similar amount of the injected fluid. In our case, the upper flow zone is very dominant. It is likely that this masks the contribution of the minor hydraulic active zones and that higher flow rates would have caused more response at fractures below the major flow zone during the injection period.

Flowmeter results suggest minor inflow zones between 2900 and $2950 \mathrm{~m} \mathrm{MD}(<1 \%$ inflow), from 3050 to $3100 \mathrm{~m} \mathrm{MD} \mathrm{(} \mathrm{1.7 \% ),} \mathrm{from} 3200$ to $3250 \mathrm{~m} \mathrm{MD} \mathrm{(} \mathrm{1.5 \% ),} \mathrm{and} \mathrm{from}$ 3250 to $3300 \mathrm{~m} \mathrm{MD} \mathrm{(} \mathrm{1.5 \% )} \mathrm{that} \mathrm{were} \mathrm{not} \mathrm{visible} \mathrm{in} \mathrm{either} \mathrm{DAS} \mathrm{nor} \mathrm{DTS} \mathrm{data} \mathrm{dur-}$ ing injection. Warm-back profiles indicate a minor hydraulically active zone at 2900 to $2950 \mathrm{~m} \mathrm{MD}$, but no statement is possible on the zones below. One explanation lies in the different flow rates of the flowmeter injection and Inj1 and Inj2. To keep the hydraulic stress on the reservoir and the mechanical/thermal stress on the sucker rod/cable construction low, flow rates of Inj1 and Inj2 were relatively low (Inj2 with 23 l/s was less than half of that of flowmeter with $50 \mathrm{l} / \mathrm{s}$ ). From velocity analysis (Fig. 9a), we have seen that the major inflow zone took almost all of the cold water. It is possible that a higher injection rate would have led to a noticeable reflection of the minor inflow zones detected by the flowmeter. As temperature changes below $3000 \mathrm{~m}$ MD during short-term injection are small, thermal anomalies caused by the injection zones are below the detection limit of DTS. However, it is expected that the DTS-temperature profile during the production will provide answers as soon as the well produces.

The acquired FO-data enhance and verify the flowmeter interpretation and show that flowmeter can still give good results under the given uncertainties-high deviation, close to liner hanger and perforated liner as described above.

\section{Conclusion and outlook}

The feasibility of installing a permanent fiber optic cable for a permanent monitoring along sucker rod into the reservoir of a deep and deviated geothermal production well was successfully demonstrated at the study site. A comprehensive database could be created that combines conventional logging data with the continuously recorded pressure, acoustic and temperature data of the innovative FO-system, allowing a long-term study 
of the geothermal reservoir. The FO-monitoring system enables a dynamic monitoring of the thermal distribution in the borehole and the reservoir when the well is set to operation, as well as acoustic studies which can be additionally addressed to the subject of monitoring the pump or microseismicity. First results that were obtained from the installed FO-monitoring system during the shut-in time and during two cold water injection tests lead to the following conclusions.

The DTS data enabled an observation of the dynamic change of thermal water temperature in the reservoir and explained the origin of an anomaly detected at the end of the wireline temperature log after well completion to be cold water remaining in the hydraulic active zone from the flowmeter test.

Conventional downhole measurements could be complemented by the FO-monitoring system, e.g., the temperature gradient was derived by the FO-monitoring system over the whole borehole length, hence also in the reservoir, while a wireline temperature logging tool got stuck and was not able to run into the reservoir at the present well deviation. Additionally, DTS measurements were used to crosscheck and correct the wireline temperature log and the $P / T$ gauge for which a processing error could be detected. Flowmeter measurements were also verified with DTS monitoring by successfully comparing the temperature response during a cold water injection and subsequent warm-back period with flowmeter data from the flow zone detection and percentage of inflow in the reservoir at the major zone. However, the flowmeter interpretation showed some uncertainties because the reservoir section is highly deviated and not open hole, but completed with a perforated liner. In addition, a major flowmeter spinner response is at a karstified zone very near to the liner hanger, where turbulence of the fluid is possible due to the well design. Hence, DTS measurements can significantly enhance the flow zone characterization qualitatively as well as quantitatively. By the dynamic long-term monitoring it is speculated that also the uncertainty of flow zone characterization can be more precisely interpreted.

Additionally, a cold water injection test revealed vertical displacement of the FO-structure. DAS data were used to verify that the thermal contraction and expansion of the sucker rod/fiber cable installation was indeed caused by the temperature decrease from cold water injection. Such thermal stress must be considered for calibration issues during future installation and installations of such FO-monitoring system with sucker rod design. These results give advice on how DTS and $P / T$ data should be processed once the well is in operation and the temperature distribution in the well changes significantly.

Although DAS monitoring of the cold water injection test Inj2 shows primarily ther$\mathrm{mal} /$ mechanical stress on the sucker rod construction, a reasonable DAS response was observed at the very beginning of Inj2 that agrees well with the injection profile from the flowmeter. However, further research is needed to determine if the signal can be translated into a velocity/injection profile.

\section{Abbreviations}

DAS: Distributed acoustic sensing; DTS: Distributed temperature sensing; PLT: Production logging tool; ESP: Electrical submersible pump; FO: Fiber optic; DOFS: Distributed optical fiber sensors; DSS: Distributed strain sensing; DPS: Distributed pressure sensing; $P / T$ : Pressure/temperature; OTDR: Optical time domain reflectometry; OFDR: Optical frequency domain reflectometry; FPI: Fabry-Perot interferometer; FBG: Fiber Bragg grating; MD: Measured depth; TVD: True vertical depth; KOP: Kick-off point; NMR: Nuclear magnetic resonance; TD: Total depth; TEF: Tubing-encased fiber; FORJ: Fiber optic rotary joint; WHO: Wellhead outlet. 


\section{Supplementary Information}

The online version contains supplementary material available at https://doi.org/10.1186/s40517-021-00204-0.

Additional file 1. Completion of the geothermal wells at Schäftlarnstraße that were used for the FO-monitoring system.

Additional file 2. Optical Time Domain Reflectometry Measurements of the FO-system in the geothermal Schäftlarnstraße site. (a): OTDR of Multi-mode fibers inside production well 1 with B and $F$ being the splice at the wellhead, $C$ and $E$ the $y$-splice at the P/T gauge and D the minibend at TD. (b): OTDR of Single-mode fibers of the looped whole system with $B$ being the minibend inside the injector well 2, C the splice at the injectors wellhead, $D$ the loss at the connector that connects the fibers of both wells, E the splice at the wellhead of the producer, $F$ the $y$-splice at the $P / T$ gauge and $G$ being the FO termination at TD.

Additional file 3. Graphical velocity analysis for cold water injection test Inj2.

Additional file 4. DTS profiles during warm-back of Inj1 in comparison to stratigraphic units and the well completion.

\section{Acknowledgements}

The fiber optic cable was installed in the course of the Geothermal Alliance Bavaria project, funded by the Bavarian Ministry of Economic Affairs, Energy and Technology. The authors would like to thank all project partners that were involved in planning and executing the FO-installation that are namely Stadtwerke München, owner and customer of the geothermal site Schäftlarnstraße, Baker Hughes, planning and executing company of the installation, Erdwerk GmbH that provided help with engineering knowledge and the drilling contractor Daldrup. From these institutions we want to thank especially Michael Meinecke (SWM), Katja Thieman and Daniel Lackner (Erdwerk GmbH) for their personal commitment for the project. Thanks also to Christian Cunow, Tobias Raab, Christopher Wollin, Charlotte Krawczyk and Ernst Huenges from the GFZ Potsdam and to the Leibniz Institut für angewandte Geowissenschaften (LIAG) that measured the conventional wireline temperature log in beforehand of the FO-installation.

\section{Authors' contributions}

FS conceptualized this work, was involved in the installation works and calibration works of the FO-system and did DTS analyses, flowmeter interpretation, visualization and wrote the original Draft. ML and TR measured DAS during the injection tests and analyzed and interpreted DAS data. They further calculated the theoretical thermal expansion from DTS. DP was involved planning, installing of the FO-monitoring system, as well as calibrating DTS. She further contributed in flowmeter interpretation. SH was responsible for planning and executing the installation of the fiber optic cable inside the wells. FE and KZ supervised the project and were involved in conceptualization. KZ was furthermore engaged in review and writing work. All authors read and approved the final manuscript.

\section{Funding}

Open Access funding enabled and organized by Projekt DEAL. This work has been performed in the framework of the project Geothermal Alliance Bavaria and is funded by the Bavarian Ministry of Science and Art.

\section{Availability of data and materials}

The datasets used and/or analyzed during the current study are available from the corresponding author on reasonable request.

\section{Declarations}

\section{Competing interests}

The authors declare that they have no competing interests.

\section{Author details}

${ }^{1}$ Chair of Hydrogeology, Technical University of Munich, Arcisstraße 21, 80333 Munich, Germany. ${ }^{2}$ Section Near-Surface Geophysics, GFZ German Research Centre for Geosciences, Telegrafenberg, 14473 Potsdam, Germany. ${ }^{3}$ Baker Hughes, Baker-Hughes-Straße 1, 29221 Celle, Germany. ${ }^{4}$ Present Address: Fraunhofer IEG, Fraunhofer Research Institution for Energy Infrastructures and Geothermal Systems IEG, Am Hochschulcampus 1, 44801 Bochum, Germany.

Received: 1 May 2021 Accepted: 18 August 2021

Published online: 03 September 2021

\section{References}

Acuña J, Mogensen P, Palm B. Distributed Thermal Response Test on a U-pipe Borehole Heat Exchanger. Applied Energy. 2009;109. https://doi.org/10.1016/j.apenergy.2013.01.02410.1016/j.apenergy.2013.01.024.

Ali L, Bentley RE, Gutierrez AA, Gonzalez Y. Using distributed temperature sensing (DTS) technology in acid gas injection design. Acta Geotech. 2013;9(1):135-44.

Angel SM, Hirschfeld TB. Fiber-optic sensors for use in the geothermal well. In: Conference on lasers and electro-optics. Optical Society of America; 1986. https://doi.org/10.1366/0003702894202922.

Banks EW, Shanafield MA, Cook PG. Induced Temperature Gradients to Examine Groundwater Flowpaths in Open Boreholes. Groundwater. 2014;52(6):943-51. https://doi.org/10.1016/S1081-1206(10)60430-9. 
Barberan C, Allanic C, Avila D, Hy-Billiot J, Hartog A, Frignet B, Lees G. Multi-offset seismic acquisition using optical fiber behind tubing. In: 74th European association of geoscientists and engineers conference and exhibition 2012 incorporating SPE EUROPEC 2012: responsibly securing natural resources. 2012. p. 11-6.

Baticci F, Genter A, Huttenloch P, Zorn R. Corrosion and scaling detection in the soultz EGS power plant, Upper Rhine Graben, France. In: Proceedings world geothermal congress 2010, Bali, Indonesia; 2010.

Bauer M, Freeden W, Jacobi H, Neu T. Handbuch tiefe geothermie prospektion, exploration, realisierung, nutzung. Berlin: Springer; 2014.

Bense VF, Read T, Bour O, Le Borgn T, Coleman T, Krause S, Chalari A, Mondanos M, Ciocca F, Selker JS. Distributed temperature sensing as a downhole tool in hydrogeology. Water Resour Res. 2008;52:1-433.

Birner J. Hydrogeologisches Modell des Malmaquifers im Süddeutschen Molassebecken. Freie Universität Berlin; 2013. Blöcher G, Reinsch T, Henninges J, Milsch H, Regenspurg S, Kummerow J, Francke H, Kranz S, Saadat A, Zimmermann G, Huenges E. Hydraulic history and current state of the deep geothermal reservoir Groß Schönebeck. Geothermics. CNR-Istituto di Geoscienze e Georisorse; 2015;17. https://doi.org/10.1016/j.geothermics.2015.07.008.

BohI W, ElmendorfW. Technische Strömungslehre: Stoffeigenschaften von Flüssigkeiten und Gasen, Hydrostatik, Aerostatik, inkompressible Strömungen, kompressible Strömungen, Strömungsmesstechnik. Munich: Vogel; 2005.

Böhm F, Savvatis A, Steiner U, Schneider M, Koch R. Lithofazielle Reservoircharakterisierung zur geothermischen Nutzung des Malm im Großraum München. Grundwasser Zeitschrift Der Fachsektion Hydrogeologie. 2013;18:3-13.

Bohnsack D, Potten M, Pfrang D, Wolpert P, Zosseder K. Porosity-permeability relationship derived from Upper Jurassic carbonate rock cores to assess the regional hydraulic matrix properties of the Malm reservoir in the South German Molasse Basin. Geothermal Energy [Internet]. 2020;8(1):12. https://doi.org/10.1186/s40517-020-00166-9.

Bremer K, Lewis E, Leen G, Moss B, Lochmann S, Müller I, Reinsch T, Schrötter J. Fibre optic pressure and temperature sensor for geothermal wells. IEEE Sensors 2010 Conference (Waikoloa, USA 2010); 2010. https://doi.org/10.1109/ ICSENS.2010.5690125.

Brown G. Downhole temperatures from optical fiber. Oilfield Rev. 2009;20(4):34-9.

Buecker C, Grosswig S. Distributed temperature sensing in the oil and gas industry-insights and perspectives. Oil Gas Eur Mag. 2017:43:209-15.

Bukhamsin A, Horne R. Cointerpretation of distributed acoustic and temperature sensing for improved smart well inflow profiling. In: Presented at the SPE western regional meeting anchorage, Alaska 23-26 May; 2016.

Cannon S. Petrophysics: a practical guide. Wiley; 2015. https://doi.org/10.1002/9781119117636.

Casper S, Bohnsack D, Zosseder K. Temperaturverteilung entlang der Malm/Purbeck-Grenze im Bayerischen Molassebecken —Prognose anhand von BHT-Korrekturverfahren. In: Holzheu St., Kaufmann-Knoke, R. \& Thies, B. Grundwasser trifft Boden und Energie. Tagungsband FH-DGG 2014. Bayreuth; 2014.

Cox B, Wills P, Kiyashchenko D, Mestayer J, Lopez J, Bourne S, Lupton R, Solano G, Henderson N, Hill D, Roy J. Distributed acoustic sensing for geophysical measurement, monitoring and verification. 2012;(February). p. 7-12.

Cverna F. ASM ready reference Thermal properties of metals. Geauga County: ASM International; 2002.

Dakin JP, Pratt DJ. Distributed optical fibre raman temperature sensor using a semiconductor light source and detector. Electronics Letters. 1985;21(13):172-4. https://doi.org/10.1016/S1081-1206(10)60430-9.

Daley TM, Berkeley L, Ajo-franklin J, Dou S, Berkeley L, Pevzner R. Field testing of fiber-optic distributed acoustic sensing (DAS) for subsurface seismic monitoring. Lead Edge. 2013;36:936-42.

DiPippo R. Geothermal power plants. Principles, applications, case studies and environmental impact. 4th ed. Oxford: Butterworth-Heinemann; 2015.

Drews M, Bauer W, Stollhofen H. Porenüberdruck im Bayerischen Molassebecken. Erdoel Erdgas Kohle/EKEP. 2018;134(7/8):308-10. https://doi.org/10.19225/18070310.19225/180703.

Eppelbaum L, Kutasov I, Pilchin A. Applied geothermics. Endeavour. Berlin: Springer; 2014

Flechtner F, Loewer M, Keim M. Updated stock take of the deep geothermal projects in Bavaria, Germany (2019). In: Proceedings World Geothermal Congress 2020 Reykjavik, Iceland, April 26-May 2, 2020 Updated; 2020.

Förster A, Schrötter J, Merriam DF, Blackwell DD. Application of optical-fiber temperature logging - An example in a sedimentary environment. Geophysics. 1997;62(4):1107-13.

Franco A, Conti P. Clearing a path for ground heat exchange systems: A review on Thermal Response Test (TRT) methods and a geotechnical routine test for estimating soil thermal properties. Energies. 2020;13(11):1-21. https://doi.org/10. 3390/en1311296510.3390/en13112965.

Freifeld B. Ground surface temperature reconstructions: Using in situ estimates for thermal conductivity acquired with a fiber-optic distributed thermal perturbation sensor. Lawrence Berkeley National Laboratory. 2008.

Frings J, Walk T. Distributed fiber optic sensing enhances pipeline safety and security. Oil Gas Eur Mag. 2011;37(3):132-6.

Fujii H, Okubo H, Itoi R. Thermal response tests using optical fiber thermometers. Geothermal Resources Council Transactions - GRC 2006 Annual Meeting: Geothermal Resources-Securing Our Energy Future. 2006. p. 545-51.

Fujii H, Okubo H, Nishi K, Itoi R, Ohyama K, Shibata K. An improved thermal response test for U-tube ground heat exchanger based on optical fiber thermometers. Geothermics. Elsevier Limited. 2009;38(4):399-406. https://doi.org/ 10.1016/j.geothermics.2009.06.002.

GeoMol Team. GeoMol - Assessing subsurface potentials of the Alpine Foreland Basins for sustainable planning and use of natural resources - Project Report. 2015:188 pp. (Augsburg, LfU). Retrieved from:https://www.geomol.eu/report? Access date: 15.04.2021.

Götz J, Lüth S, Henninges J, Reinsch T. Vertical seismic profiling using a daisy-chained deployment of fibre-optic cables in four wells simultaneously — case study at the Ketzin carbon dioxide storage site. Geophys Prospect. 2018;66(6):1201-14.

Grant MA, Bixley PF. Geothermal reservoir engineering. 2nd ed. New York: Academic Press; 2011.

Haoua TB, Abubakr S, Pazzi J, Djessas L, Ali AM, Ayyad HB, Boumali A. Combining horizontal production logging and distributed temperature interpretations to diagnose annular flow in slotted-liner completions. 2015, p. 1-13.

Hartog AH. An Introduction to Distributed Optical Fibre Sensors. Edition, 1. CRC Press; 2017. https://doi.org/10.1201/ 9781315119014 
Hartog A, Frignet B, Mackie D, Clark M. Vertical seismic optical profiling on wireline logging cable. Geophys Prospect. 2014:62:693-701.

Heine F, Zosseder K, Einsiedl F. Hydrochemical Zoning and Chemical Evolution of the Deep Upper Jurassic Thermal Groundwater Reservoir Using Water Chemical and Environmental Isotope Data. Water. 2021;13(9).

Henninges J, Zimmermann G, Schrötter J, Erbas K, Huenges E. Wireline distributed temperature measurements and permanent installations behind casing. In: Proceedings world geothermal congress; 2005. p. 24-9.

Hole H. Geothermal well completion tests. Petroleum engineering summer school; 2008;(June)p. 1-5. https://pangea. stanford.edu/ERE/pdf/IGAstandard/ISS/2008Croatia/Hole03.pdf.

Homuth S. Aufschlussanalogstudie zur Charakterisierung oberjurassischer geothermischer Karbonatreservoire im Molassebecken. Darmstadt: Technische Universität Darmstadt; 2014.

Hurtig E, Großwig S, Jobmann M, Kühn K, Marschall P. Fibre-optic temperature measurements in shallow boreholes: experimental application for fluid logging. Geothermics. 1994;23(4):355-64. https://doi.org/10.1016/0375-6505(94) 90030-2.

Hurtig E, Großwig S, Kühn K. Fibre optic temperature sensing: Application for subsurface and ground temperature measurements. Tectonophysics. 1996;257(1 SPEC. ISS.):101-9. https://doi.org/10.1016/0040-1951(95)00124-7.

IGA Services GmbH. Best practices guide for geothermal exploration; 2014. http://documents1.worldbank.org/curated/ en/190071480069890732/pdf/110532-Geothermal-Exploration-Best-Practices-2nd-Edition-FINAL.pdf. Accessed 15 Apr 2021.

Inaudi D, Glisic B. Long-range pipeline monitoring by distributed fiber optic sensing. J Pressure Vessel Technol Trans ASME. 2010;132(1):0117011-9.

James JD, Spittle JA, Brown SGR, Evans RW. A review of measurement techniques for the thermal expansion coefficient of metals and alloys at elevated temperatures. Meas Sci Technol. 2001;12(3):1-15.

Johnson DO, Sierra JR, Kaura JD, Gualtieri D. Successful flow profiling of gas wells using distributed temperature sensing data. In: SPE annual technical conference and exhibition, San Antonio, Texas, USA, September 2006. 2006. https:// doi.org/10.2118/103097-MS.

Kavvadias K, Jiménez-Navarro JP, Thomassen G. Decarbonising the EU heating sector. Luxembourg; 2019.

Kenkmann T, Hesse T, Hülsmann F, Timpe C, Hoppe K. Klimaschutzziel und_-strategie München 2050 Endbericht. Freiburg; 2017.

Kersey AD. Optical fiber sensors for permanent downwell monitoring applications in the oil and gas industry. IEICE Trans Electr. 2000;E83(3):400-4.

Koch A, Clauser C, Hartmann A, Jorand R, Rath V, Wolf A, Mottaghy D, Pechnig R. Erstellung statistisch abgesicherter thermischer und hydraulischer Gesteinseigenschaften für den flachen und tiefen Untergrund in Deutschland Phase 1-Westliche Molasse und nördlich angrenzendes Süddeutsches Schichtstufenland; 2006.

Köhl B, Grundy J, Baumann T. Rippled scales in a geothermal facility in the Bavarian Molasse Basin : a key to understand the calcite scaling process. Geothermal Energy. Berlin: Springer; 2020;8:23:27. https://doi.org/10.1186/ s40517-020-00177-6.

Konrad F, Savvatis A, Degen D, Wellmann F, Einsiedl F, Zosseder K. Productivity enhancement of geothermal wells through fault zones: efficient numerical evaluation of a parameter space for the Upper Jurassic aquifer of the North Alpine Foreland Basin. Geothermics. 2021. https://doi.org/10.1016/.geothermics.2021.102119.

Konrad F, Savvatis A, Wellmann F, Zosseder K. Hydraulic behavior of fault zones in pump tests of geothermal wells : a parametric analysis using numerical simulations for the Upper Jurassic aquifer of the North Alpine Foreland Basin. Geothermal Energy [Internet]. Springer Berlin Heidelberg; 2019. https://doi.org/10.1186/s40517-019-0137-4.

Latal J, Koudelka P, Siska P, Skapa J, Hanáeck F, Vasinek V, et al. Fiber optic DTS system application in the research of accumulation possibilities of thermal energy in the rock mass. Proceedings of SPIE - The International Society for Optical Engineering. 2011. https://doi.org/10.1117/12.88708210.1117/12.887082.

Liang M, Fang X, Ning Y.Temperature Compensation Fiber Bragg Grating Pressure Sensor Based on Plane DiaphragmTemperature Compensation Fiber Bragg Grating Pressure Sensor Based on Plane Diaphragm.Photonic Sensors. 2018;8(2):157-167. https://doi.org/10.1007/s13320-018-0417-9.

Lipus MP, Schölderle F, Reinsch T, Wollin C, Krawxzyk CM, Pfrang D, Zosseder K. Dynamic motion monitoring of a $3.6 \mathrm{~km}$ long steel rod in a borehole during cold-water injection with distributed fiber-optic sensing. Solid Earth Discuss. [preprint]; 2021; https://doi.org/10.5194/se-2021-63, in review, 2021.

Lumens PGE. Fibre-optic sensing for application in oil and gas wells. Eindhoven University of Technology. 2014. https:// doi.org/10.6100/IR769555

Madsen KN, Tondel R, Kvam O. Data-driven depth calibration for distributed acoustic sensing. Lead Edge. 2016:35(7):562-648.

Majorowicz JA, Smith SL. Review of ground temperatures in the Mallik field area: A constraint to the methane hydrate stability. Bull Geol Surv Canada. 1999:544:45-56.

Masoudi A, Newson TP. Contributed review: distributed optical fibre dynamic strain sensing. Rev Sci Instrum. 2016. https://doi.org/10.1063/1.4939482.

Masoudi A, Belal M, Newson TP. A distributed optical fibre dynamic strain sensor based on phase-OTDR. Meas Sci Technol. 2013;24:8.

Meyer RKF, Schmidt-Kaler H. Paläogeographie und Schwammriffentwicklung des süddeutschen Malm- ein Überblick paleogeography and development of sponge reefs in the Upper Jurassic of Southern Germany - an overview. 1990 p. $175-84$.

Mraz E. Reservoir characterization to improve exploration concepts of the Upper Jurassic in the Southern Bavarian Molasse Basin. Munich: Technische Universität München; 2018.

Naldrett G, Cerrahoglu C, Mahue V. Production monitoring using next-generation distributed sensing systems. Petrophys SPWLA J Format Eval Reserv Descrip. 2018;59(4):496-510. https://doi.org/10.30632/PJV59V4-2018a5.

Nath DK, Finley DB, Kaura JD. Real-time fiber-optic distributed temperature sensing (DTS)-new applications in the oilfield. In: SPE annual technical conference and exhibition, San Antonio, Texas, USA, September 2006; 2006. https://doi.org/ 10.2118/103069-MS. 
Paleja R, Mustafina D, in 't panhuis P, Park T, Randell D, Van der Horst J. Velocity tracking for flow monitoring and production profiling using distributed acoustic sensing. Society of Petroleum Engineers; 2015.

Patterson J, Cardiff M, Coleman T, Wang H, Feigl K, Akerley J, Spielman P. Geothermal reservoir characterization using distributed temperature sensing at Brady Geothermal Field, Nevada. Lead Edge. 2017;36:1024a1-1027.

Qi B, Pickrell G, Zhang P, Duan Y, Peng W, Xu J, Huang Z, Deng J, Xiao H, Wang Z, Huo W, May RG, Wang A. Fiber optic pressure and temperature sensors for oil down hole application. In: Proceedings of SPIE-the international society for optical engineering; 2002. 4578(February).

Reinsch T, Henninges J. Temperature dependent characterization of optical fibres for distributed temperature sensing in hot geothermal wells. Measurement Science \& Technology - MEAS SCI TECHNOL. 2012; 21. https://doi.org/10.1088/ 0957-0233/21/9/0940222.

Reinsch T, Henninges J, Ásmundsson R. Thermal, mechanical and chemical influences on the performance of optical fibres for distributed temperature sensing in a hot geothermal well. Environ Earth Sci. 2013;70(8):3465-80.

Sakaguchi K, Matsushima N. Temperature logging by the distributed temperature sensing. proceedings world geothermal congress 2000, Kyushu—Tohoku, Japan, May 28-June 10, 2000. 2000. p. 1657-61.

Sanders PE. Fiber-optic sensors: playing both sides of the energy equation. Opt Photon News OSA. 2011;22(1):36-42.

Schlumberger. Cased hole log interpretation principles/applications. 4th ed. Schlumberger: Pennsylvania State University; 1997.

Sharma SK, Seki K, Angel SM, Garvis DG. Field Testing of an optical fibre tempertaure sensor in a geothermal well. Geothermics 1990;19(3):285-94.

Siska P, Latal J, Bujok P, Vanderka A, Klempa M, Koudelka P, et al. Optical fiber based distributed temperature systems deployment for measurement of boreholes temperature profiles in the rock massif. Optical and Quantum Electronics. 2016; 48. https://doi.org/10.1007/s11082-016-0379-3.

Smithpeter C, Normann R, Krumhansl J, Benoit D, Thompson S. Evaluation of a distributed fiber-optic temperature sensor for logging wellbore temperature at the Beowawe and Dixie Valley geothermal fields. In: Twenty-fourth workshop on geothermal reservoir engineering. 1999; http://www.geothermal-energy.org/pdf/IGAstandard/SGW/1999/Smith pet.pdf. Accessed 15 Apr 2021

Smolen JJ, Spek A Van Der. A DTS Primer for Oil \& Gas Production. Tech.Report, Shell. 2003.

Steiner U, Savvatis A, Böhm F, Schubert A. Explorationsstrategie tiefer geothermischer Ressourcen am Beispiel des süddeutschen Oberjura. Handbuch Tiefe Geothermie. Bauer et al.; 2014. p. 421-61.

Ukil A, Braendle H, Krippner P. Distributed temperature sensing: review of technology and applications. IEEE Sens J. 2012;12(5):885-92.

Weber J, Born H, Moeck I. Geothermal energy use, country update for Germany 2016-2018. In: European geothermal congress 2019, Den Haag, The Netherlands, 11-14 June 2019. 2019. p. 11-4.

Williams T, Lee E, Chen J, Wang X, LerohI D, Armstrong G, Hilts Y. Fluid ingress location determination using distributed temperature and acoustic sensing. In: Society of petroleum engineers - SPE digital energy conference and exhibition 2015. 2015; (Jacobs 2014):554-67.

Wisian KW, Blackwell DD, Bellani S, Henfling JA, Normann RA, Lysne PC, Förster A, Schrötter J. Field comparison of conventional and new technology temperature logging systems. Geothermics. 1998;27(2):131-41.

Wolfgramm M, Obst K, Beichel K, Brandes J, Koch R, Rauppach K, et al. Produktivitätsprognosen geothermischer Aquifere in Deutschland. Beitrag "Der Geothermiekongress 2009" Bochum, Germany, 17-19 November 2009. 2009. p. 17-9.

Wyllie MRJ, Gregory AR, Gardner LW. Elastic wave velocities in heterogeneous and porous media. Geophysics. 1956;21(1):41-70. https://doi.org/10.1190/1.1438217.

Zarrouk SJ, McLean K. Geothermal well test analysis fundamentals, application and advanced techniques. Hoboken: Elsevier; 2019.

Zhou X, Yu Q, Peng W. Simultaneous measurement of down-hole pressure and distributed temperature with a single fiberSimultaneous measurement of down-hole pressure and distributed temperature with a single fiber. Measurement Science and TechnologyMeasurement Science and Technology. 2012;23. https://doi.org/10.1088/0957-0233/ 23/8/085102.

\section{Publisher's Note}

Springer Nature remains neutral with regard to jurisdictional claims in published maps and institutional affiliations.

\section{Submit your manuscript to a SpringerOpen ${ }^{\circ}$ journal and benefit from:}

- Convenient online submission

- Rigorous peer review

- Open access: articles freely available online

- High visibility within the field

- Retaining the copyright to your article

Submit your next manuscript at $\boldsymbol{\nabla}$ springeropen.com 